\title{
Managing Sovereign Credit Risk in Bond Portfolios*
}

\author{
Benjamin Bruder \\ Research \& Development \\ Lyxor Asset Management, Paris \\ benjamin . bruder@lyxor . com
}

\author{
Pierre Hereil \\ Research \& Development \\ Lyxor Asset Management, Paris \\ pierre.hereil@lyxor.com
}

\author{
Thierry Roncalli \\ Research \& Development \\ Lyxor Asset Management, Paris \\ thierry.roncalli@lyxor.com
}

October 2011

\begin{abstract}
With the recent development of the European debt crisis, traditional index bond management has been severely called into question. We focus here on the risk issues raised by the classical market-capitalization weighting scheme. We propose an approach to properly measure sovereign credit risk in a fixed-income portfolio. For that, we assume that CDS spreads follow a SABR process and we derive a sovereign credit risk measure based on CDS spreads and duration of portfolio bonds. We then consider two alternative weighting methods which are fundamental indexation and risk-based indexation. Fundamental indexation is based on GDP indexation whereas risk-based indexation uses a risk budgeting approach based on our sovereign credit risk measure. We then compare all these methods in terms of risk, diversification and performance. We show that the risk budgeting approach is the most appropriate scheme to manage sovereign credit risk in bond portfolios and gives very appealing results with respect to active management of bond portfolios.
\end{abstract}

Keywords: Sovereign credit risk, credit spread, convex risk measure, sabr model, CDS, bond indices, fundamental indexation, risk-based indexation, risk budgeting.

JEL classification: G11, C58, C60, H63.

\section{Introduction}

The impact of the European debt crisis may be huge. From an economic point of view, we know that economic growth, inflation and foreign exchanges are and will be highly affected for a long time. Today, there is a lot of uncertainty about the economic and fiscal policies that Europe and the rest of the world will adopt. Some risk scenarios are more plausible than others, but nobody knows what the final outcome will be. From a financial investment point

*This paper is an extended version of the article "Managing Sovereign Credit Risk" published in Journal of Indexes Europe. 
of view, the European crisis questions investment policies of pension funds, institutionals and even retail investors. For example, there is a big issue on strategic asset allocation and long-term investment policy, because the allocation between asset classes depends on two economic pillars, namely the output and the inflation (Eychenne et al., 2011). A stagnation risk scenario will then not produce the same results as an inflation risk scenario in terms of the equity/bond asset mix decision.

Another consequence of the the European debt crisis is its impact on bond portfolio management. Indeed, pension funds and institutionals are massively invested in bonds, and in particular sovereign bonds. For a long time, sovereign bonds of developed countries have been considered a safe asset. This is especially true since the creation of the eurozone and European investors have largely diversified their portfolios by investing in non-domestic bonds since 2000. The stability of the eurozone over the last decade explains this phenomenon: a European investor could prefer Italian bonds to German bonds, because they offered a better return for a risk increment which was considered to be negligible. Until recently, bond management in the eurozone was then principally explained by the search of spread. This style of active management has been encouraged by the industry of passive management with benchmarks and indexes based on debt weightings. But the eurozone crisis and the rediscovery of the sovereign credit risk leads to rethink the management of bond portfolios by giving a better place to risk management.

The paper is organized as follows. In section two, we define precisely the sovereign risk and explain why country risk is so specific with respect to other risks. In section three, we give some insight about the properties of a good sovereign credit risk measure. It allows to define a risk measure which is consistent from a theoretical point of view and which could be used in practice for bond portfolios. We then apply this risk measure to analyse market-cap weighted bond indexes. In section four, we consider how fundamental indexation and risk-based indexation could correct the drawbacks of market-capitalization indexation with regard to our sovereign credit risk measure. Section five presents a comparative analysis between the three indexation schemes (debt-capitalization, fundamental and risk-based indexations). Finally, section six offers some concluding remarks.

\section{Rediscovering sovereign credit risk}

In August 2011 Standard and Poor's downgraded the credit rating of US government debt from AAA for the first time. Even five years ago, such an event would have seemed very unlikely; historically, the debt of major developed countries has been considered almost free of credit risk. However, the 2008 financial crisis and the resulting global recession has played havoc with this conception. Sovereign issuers' creditworthiness is now under increasing scrutiny, especially in Europe, while bond investors now face a significant new challenge, one that's especially important for those using a passive, index-based approach.

\subsection{The country risk}

Sovereign default risk has a long history. Recent debt crises, such as those in 1982 (Mexico and Latin America), 1997-1998 (Russia and Asia) or 2001 (Argentina and Turkey), have been concentrated on emerging markets. Nevertheless, it's been many decades since a "developed" country defaulted. According to Reinhart and Rogoff (2009), there have been at least 250 sovereign external defaults and 68 defaults on domestic public debt since 1800 . 
Generally, country risk encompasses three types of risk covering financial economic crises (e.g. the 2008 subprime crisis), external debt defaults (e.g. the 1997 Russian default) and banking system (e.g. the 1990 Swedish crisis). One thing these crises have in common is that they generally occur in highly leveraged economies. Kindleberger $(1939,1978)$ has extensively studied these crises and observes that they show the same patterns. It starts with a period of overenthusiasm followed by a period of loss of confidence. The crisis is then triggered by credit rationing and its impact on the business cycle. Reinhart and Rogoff (2009) have called these patterns the "syndrome of this-time-is-different":

The essence of this-time-is-different syndrome is simple. It is rooted in the firmly held belief that financial crises are things that happen to other people in other countries at other times; crises do not happen to us, here and now. We are doing things better, we are smarter, we have learned from past mistakes. The old rules of valuation no longer apply. The current boom, unlike the many booms that preceded catastrophic collapses in the past (even in our country), is built on sound fundamentals, structural reforms, technological innovations, and good policy. Or so the story goes [...] Unfortunately, a highly leveraged economy can unwittingly be sitting with its back at the edge of a financial cliff for many years before chance and circumstance provoke a crisis of confidence that pushes it off.

One of the problems with a sovereign crisis is that the time to recovery may be very long compared to a crisis caused by a pure financial bubble (e.g. the dot.com episode) or by corporate defaults. The main reason is that a firm or an economic sector can deleverage quickly, but not a country. Another problem is the contagion effect. Wyplosz (1999) argues that the market is not perfect and the failures of the market produce multiple equilibria (bad/good). In this context, contagion may appear naturally even if fundamentals of the economy are good. In the end, the main problem of sovereign crises is that the economic cost may be huge ${ }^{1}$.

\subsection{The eurozone crisis: a debt crisis or a Euro crisis?}

The eurozone crisis finds its roots in the US subprime crisis in 2007-2008. After the bankruptcy of Lehman Brothers in September 2008 and the fear of "the return of depression economics" (Krugman, 2009), European countries have largely participated to the G20 global spending plan. One of these Keynesian stimulus consequences is that European debt has dramatically increased during the period 2009-2011. In Figure 1, we have represented the evolution of the eurozone debt market value ${ }^{2}$. In two years, from November 2008 to November 2010 , the debt market value increased by $38 \%$. This is larger than the $33 \%$ increase which took place during the preceding nine years, between January 2000 and November 2008.

Another factor which explains the eurozone crisis is the status of Greece. In October 2009, Prime Minister George Papandreou warns that the finances of his country are in a "state of emergency". In April 2010, Greece sovereign debt rating is cut to BB+. In May 2010, Greece receives a first bailout from EU and IMF. However, this plan is not sufficient and a new bailout is decided in July 2011. With the case of Greece, EU has shown its lack

\footnotetext{
${ }^{1}$ Argentina (55\% of GDP, 1980-82), Japan (10\% of GDP, 1990s), Chile (41\% of GDP, 1981-87), Israel (30\% of GDP, 1977-83), United States (3\% of GDP, 1980s), Sweden (10\% of GDP, 1990-93), etc. (Crockett 1997, Wyplosz 1999).

${ }^{2}$ We have estimated the monthly growth rate of the European debt by using a cubic spline exponential model.
} 
Figure 1: Evolution of the eurozone debt market value (in MEUR)

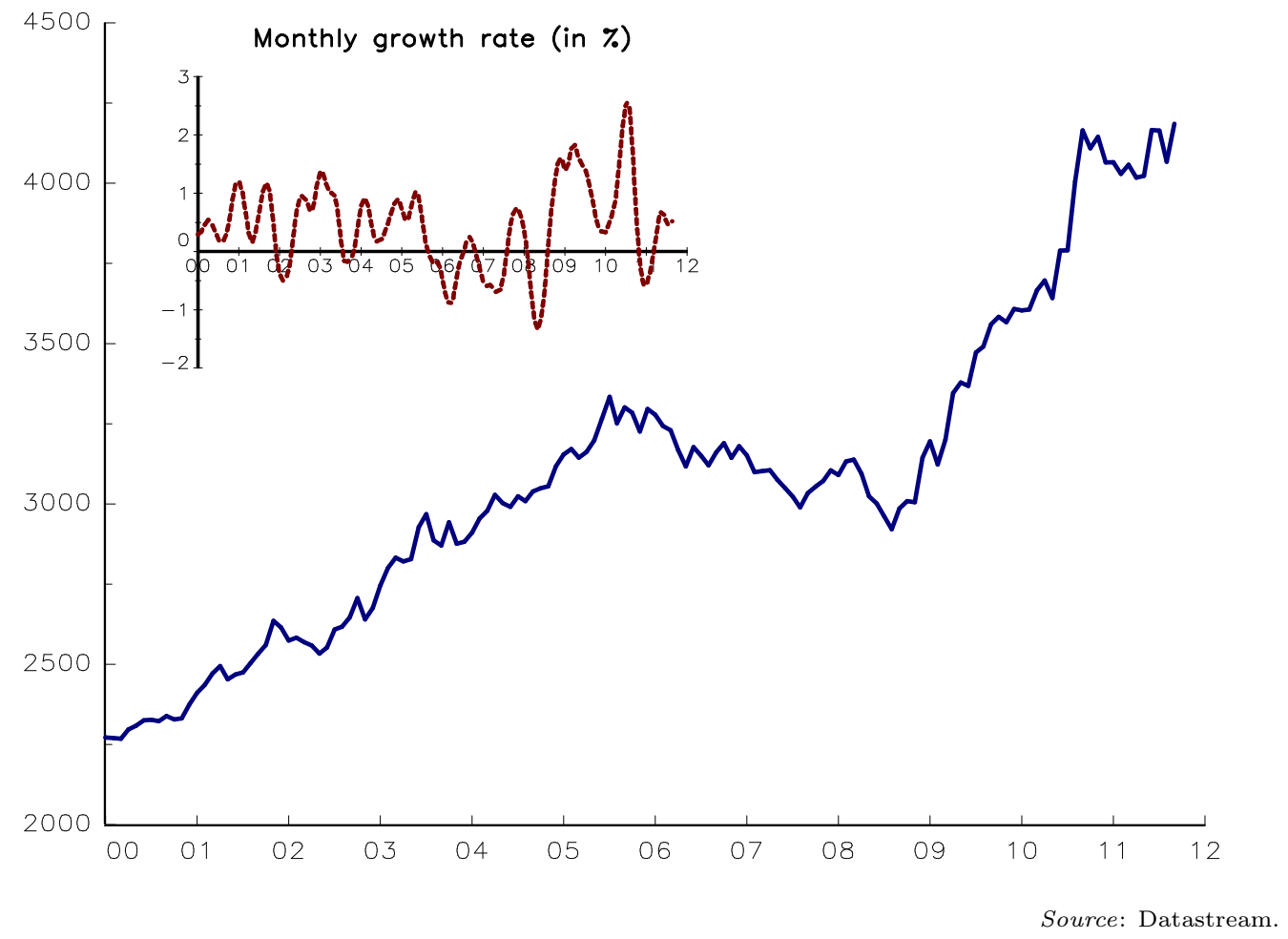

of coordination and reaction. However, Wyplosz (1999) argues that hesitations may be a factor of contagion. The later the decision, the lower the credibility and the greater this crisis.

The European crisis is not only a crisis of debt sustainability. It is also a crisis of the Euro currency. In 1961, Mundell develops the theory of optimal currency area which describes the optimal characteristics for the creation of a currency or a monetary union. To drive an economic policy and to face a crisis, there are several instruments and ajustement variables like foreign exchange rates, supply of money, prices/wages or inflation/unemployment tradeoffs. If a monetary union is created, it loses the control over foreign exchange rates. In this case, an external balance deficit cannot be compensated by a depreciation of the currency and will eventually lead to higher unemployment. Because a monetary union could be viewed as a region where the exchange rate is fixed inside and flexible outside, participants of the monetary union must share some common principles as explained by Mundell:

If the world can be divided into regions within each of which there is factor mobility and between which there is factor immobility, then each of these regions should have a separate currency which fluctuates relative to all other currencies.

This is the idea behind the Maastricht Treaty and the Stability and Convergence Programmes (SCP). They lay down the common rules applicable to the European countries in order to ensure the convergence of fiscal and economic policies. However, most of these common rules are not respected. In some sense, the Eurozone crisis is not only a debt crisis, but also the crisis of the Euro. 


\subsection{Sovereign credit risk in bond indices}

Traditionally, bond indices have been constructed according to the methodology of weighting by market capitalisation. This means that each country in the index is given a weight proportional to its level of outstanding debt ${ }^{3}$. The simplicity of this approach and the recognition of a capitalisation-weighted index as the "market portfolio" has contributed to the success of the methodology. Yet, intuitively, it is easy to note a basic flaw in this allocation scheme, since it gives higher index weightings to the most indebted countries, regardless of their capacity to service their debt. A country facing financial hardship and trapped in a debt spiral to remain solvent would see its index weight increase until the whole mechanism collapses and an exclusion from the index occurs. Depending on the index, exclusion can be triggered by specific events, such as a downgrade or, in the worst case, a default.

The case of Greece illustrates this point. Since the beginning of the financial crisis, Greece has struggled with a high debt and refinancing burden. As the country relied more and more on borrowing, the weight of Greek debt increased in European bond indices until the point where Greece was downgraded and excluded from some of the key indices. Passive investors then had no choice but to sell their distressed bonds into a depressed market, leading to significant losses. From the perspective of efficient markets theory, such a risk could be acceptable if it were compensated by an additional return, resulting in similar risk-adjusted returns from the debt of different countries. However, this does not seem to be verified in practice, as Robert Arnott has pointed out (2010).

Another approach to bond indexing is to base weightings on fundamental data. The underlying idea is that weightings should reward those countries with high income, rather than those with high levels of debt. Toloui (2010) proposes to weight country exposures by GDP instead of by outstanding debt. This approach has the advantage of addressing some of the shortcomings of capitalisation-weighted indices:

- it allocates more to less indebted countries;

- it does not have a backward-looking bias, unlike capitalisation-weighted indices (which reflect past patterns of debt issuance);

- it does not suffer from the "buy high, sell low" problem characteristic of the capitalisationweighted approach.

Both these weighting schemes integrate fundamental data in an attempt to allocate more to countries less likely to default, leading eventually to risk mitigation. Here fundamental factors are used as basic sovereign risk indicators. More comprehensive indicators could also be considered ${ }^{4}$. Brodsky et al. (2011) present the Blackrock Sovereign Risk Index, which is based on a wide range of fundamental factors, both quantitative and qualitative. Agencies' credit ratings are certainly the most established type of sovereign risk indicator. These ratings, although mainly driven by fundamental metrics, as shown by Cantor and Packer (1996), put a greater emphasis on discretionary analysis. Finally Gray et al. (2007) offer an alternative to scoring/discretionary models. They adapt Merton's seminal work (1974) on corporate credit ratings to derive a sovereign risk indicator for emerging markets. From a pragmatic standpoint, all these risk indicators have proven to be correlated significantly

\footnotetext{
${ }^{3}$ In the rest of the article the terms "capitalisation-based" and "debt-based" are used interchangeably to refer to such a weighting scheme.

${ }^{4}$ For example, Hilscher and Nosbusch (2010) consider not only the absolute level of fundamentals but also the volatility of fundamentals.
} 
with the credit default swap (CDS) or yield spreads observed in the markets. Such indicators could therefore be deemed reliable as inputs for a weighting scheme.

Whichever approach one chooses, measuring sovereign risk is a prerequisite for anyone running a government bond portfolio. Below, we suggest a theoretical framework for such a measurement.

\section{Measuring the risk of sovereign bond portfolios}

The volatility of prices return, a measure traditionally used for equity risk, cannot be applied to sovereign bonds. Instead of measuring the specific risk of a sovereign country, volatility will also reflect global movements in interest rate yield curves. Even if we consider a portfolio of sovereign bonds following a single yield curve, the constituent bonds will react differently to interest rate movements, due to their differing sensitivities (duration and convexity). For instance, low duration bonds will consistently display lower volatilities than longer duration bonds, regardless of their credit risk. The same conclusion applies when price returns are used to measure bonds' co-movements through a computation of correlations. As our interest lies in discriminating among countries on the basis of their credit risk, and not on issuespecific features, we must turn to other risk measures.

In Table 1, we have reported some popular measures of country risk. The first one is the rating given by credit rating agencies like Standard and Poor's, Moody's Investors Service or Fitch Ratings. The second one corresponds to the measure computed by Euromoney whereas the third one is the opacity score developed by the Milken Institute. All these three measures are very interesting, but are difficult to use to define a risk measure. For example, the last two measures do not measure exactly the default of sovereign debt. Ratings are better for that, but there is inertia in revising these ratings. Moreover, there are some evidence that rating movements lag market-based indicators (Di Cesare, 2006). In Table 1, we have also reported the CDS spreads of several countries for September $1^{\text {st }}, 2011$ and October $4^{\text {th }}, 2011$. For example, the downgrades of Spain and Italy during the first two weeks of October seem to be anticipated by the CDS market.

\subsection{Defining the risk measure}

The use of a coherent convex risk measure is important. We consider a portfolio of $n$ assets and we denote by $x_{i}$ the weight of the $i^{\text {th }}$ asset in the portfolio. Let $\mathcal{R}\left(x_{1}, \ldots, x_{n}\right)$ be the risk measure which depends on the portfolio weights $x=\left(x_{1}, \ldots, x_{n}\right)$. We say that $\mathcal{R}$ is a coherent convex risk measure if it satisfies this mathematical property:

$$
\mathcal{R}\left(x_{1}, \ldots, x_{n}\right)=\sum_{i=1}^{n} x_{i} \cdot \frac{\partial \mathcal{R}\left(x_{1}, \ldots, x_{n}\right)}{\partial x_{i}}
$$

This property is called the Euler decomposition of the risk measure. It means that the risk of the portfolio may be decomposed as a sum of the weights times the marginal risks. In this case, we may define exactly what the risk contribution of each asset is:

$$
\mathrm{RC}_{i}=x_{i} \cdot \frac{\partial \mathcal{R}\left(x_{1}, \ldots, x_{n}\right)}{\partial x_{i}}
$$

Working with convex risk measures simplifies the risk analysis of the portfolio, because we may attribute to each asset its contribution to the global portfolio risk. 


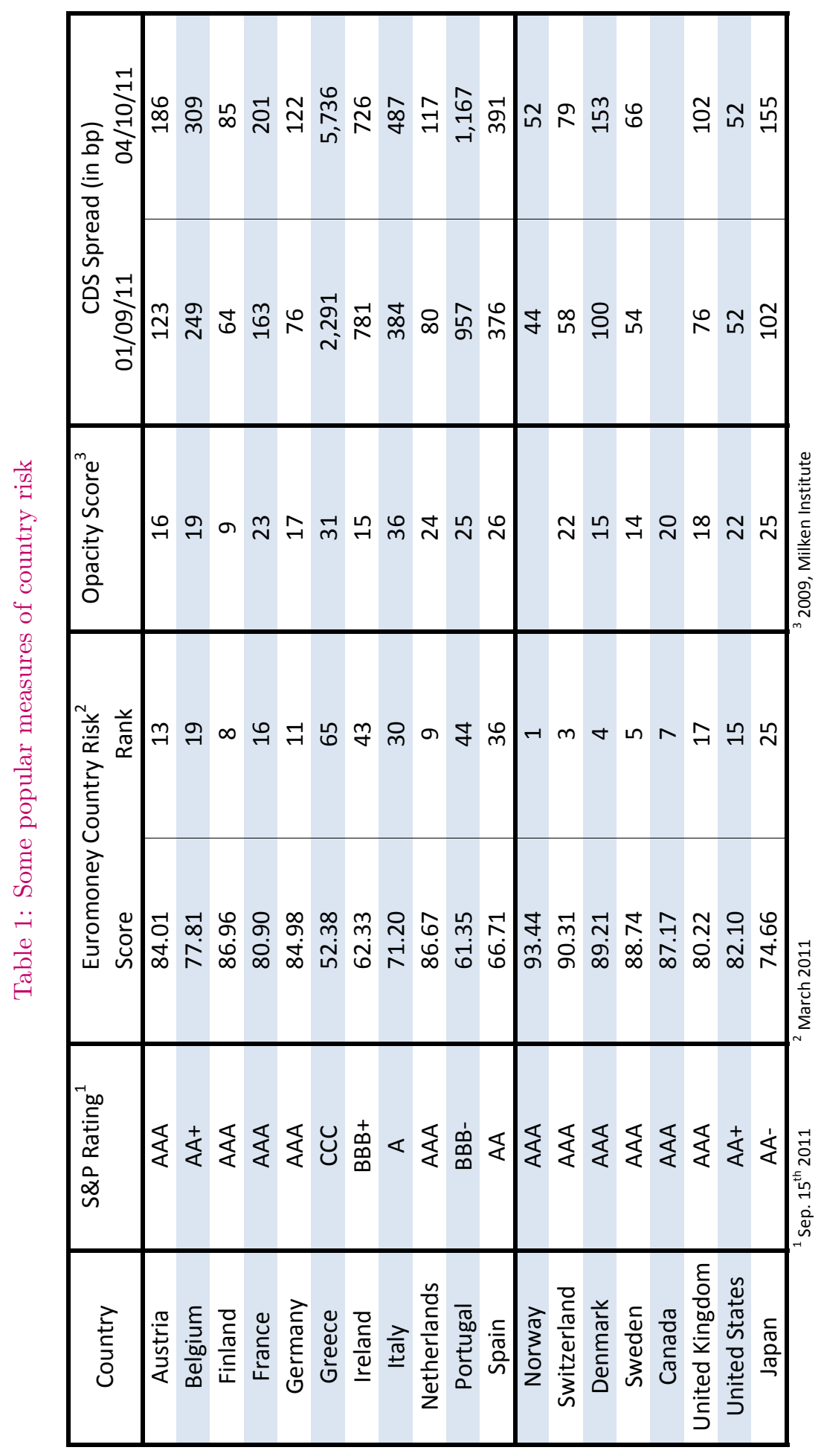


Bond prices may not be directly used for our purpose, but yields derived from them might. When compared with a reference risk-free rate at corresponding maturities, yield spreads act as an incremental return, compensating the investor for the risk associated with the issuer. Ceteris paribus, the higher the yield spread, the higher the credit risk. Unlike price returns, this measure does not depend on a bond's duration or convexity. However, it is not obvious what reference rate should be used or which maturity should be chosen. An alternative to using bond yield spreads is to use CDS spreads, which exempt us from selecting a reference rate for each issue under study ${ }^{5}$. CDS spreads correspond to the value investors are willing to pay to insure against an issuer's default risk. CDS spreads therefore allow us to isolate the sovereign credit risk of an issue, regardless of its currency, yield curve or maturity ${ }^{6}$.

\subsection{Modelling the dynamics of the spreads}

Let $S_{i}(t)$ be the spread of the $i^{\text {th }}$ country. We assume that it follows the following diffusion SABR process (Hagan et al., 2002):

$$
\mathrm{d} S_{i}(t)=\sigma_{i}^{S} \cdot S_{i}(t)^{\beta_{i}} \cdot \mathrm{d} W_{i}(t)
$$

Using historical observations of spreads we can calibrate the parameters $\sigma_{i}^{S}$ and $\beta_{i}$ by the log-likelihood function. Here we consider the CDS spreads of the eleven European countries belonging to the Citigroup European Government Bond Index (EGBI) since January 2008. We obtain values for $\beta_{i}$ close to one ${ }^{7}$. For simplicity's sake we will assume that the spreads follow a lognormal diffusion in the rest of the article. This implies that spreads vary proportionally to their absolute levels. This assumption seems reasonable in view of CDS spread data over the last few years. Moreover the credit risk component of bond volatility is thus proportional to its spread ${ }^{8}$. It can be estimated as the product of its duration $D_{i}$, the spread volatility $\sigma_{i}^{S}$ and the spread level $S_{i}(t)$ :

$$
\sigma_{i}^{B}=D_{i} \cdot \sigma_{i}^{S} \cdot S_{i}(t)
$$

Finally we model state-dependence, defining $\Gamma$ as the correlation matrix of the Brownian motions $W_{i}(t)$. Therefore, $\Gamma$ can be estimated by computing the empirical correlation matrix of the relative variations of historical spreads. The credit risk of a portfolio of $n$ sovereign bonds is then defined as the volatility of the CDS basket which would perfectly hedge the sovereign risk of the portfolio:

$$
\mathcal{R}(x)=\sqrt{x^{\top} \Sigma x}
$$

where $\Sigma_{i, j}=\Gamma_{i, j} \cdot \sigma_{i}^{B} \cdot \sigma_{j}^{B}$ is the the covariance between the bond of country $i$ and the bond of country $j$ and $x$ is the vector of country weights.

\footnotetext{
${ }^{5}$ One drawback of this measure is that the CDS market is less liquid than the bonds market. Perhaps a better measure may be the asset swap spread, but it implies some calibration issues. For the purpose of this paper, the use of CDS spreads is sufficient to illustrate our methodology.

${ }^{6}$ This approach is frequently used by recent studies on this subject (Longstaff et al., 2007, Ejsing and Lemke, 2011).

${ }^{7}$ Results are given in Appendix A.1. We obtain an average value of 0.957 if we consider the 11 countries.

${ }^{8}$ Let $B_{i}\left(t, D_{i}\right)$ be a zero-coupon risky bond of maturity (or duration) $D_{i}$. We have:

$$
\mathrm{d} \ln B_{i}\left(t, D_{i}\right)=-D_{i} \cdot \mathrm{d} R(t)-D_{i} \cdot \mathrm{d} S_{i}(t)
$$
}

with $R(t)$ the "risk-free" interest rate. 


\subsection{Some stylized facts}

In Tables 2, 3 and 4, we report the estimated values of the $\sigma_{i}^{S}$ and $\Gamma_{i, j}$ parameters for the 11 member countries of the euro for different dates. In September 2011, we notice that the spread volatilities $\sigma_{i}^{S}$ seem to fluctuate around $60 \%$, ranging from $53 \%$ to $70 \%$ and crosscorrelations tend to cluster around $65 \%$. We also remark that Finland, which is the country with the lowest level of debt, relative to the size of its economy, is the least correlated with the other markets. At the opposite end of the scale, Portugal, Italy, Greece and Spain, four of the most heavily indebted European countries, exhibit a high level of correlation between each other. This could confirm the intuition that contagion would be more likely to spread among such indebted countries, whereas countries such as Finland would be less susceptible to the default of other Eurozone countries. Comparing these estimates to those from three years earlier, we obtain different results for volatility and correlation. In July 2008, the spread volatility fluctuated between $58 \%$ and $107 \%$, with an average of $77 \%$. This is due to the log-normality model property of the spread process: the smaller the spreads, the larger the (relative) volatility. As for the correlations, we notice a sharp increase. The average correlation rose from 38\% in January 2008 to $62 \%$ in September 2011. In Figure 2, we have reported the evolution of the $\Gamma$ matrix. We observe some interesting facts. First, the default of Lehman Brothers has shifted the average correlation. It is particularly obvious for the safe countries like Finland, Germany and Netherlands. Second, we also observe that the correlation between GIIPS reaches its maximum in October 2010, and decreases since this date. Third, the correlation between safe countries (Finland, Germany and Netherlands) has increased recently illustrating a period of flight-to-quality.

Figure 2: Evolution of the $\Gamma$ matrix

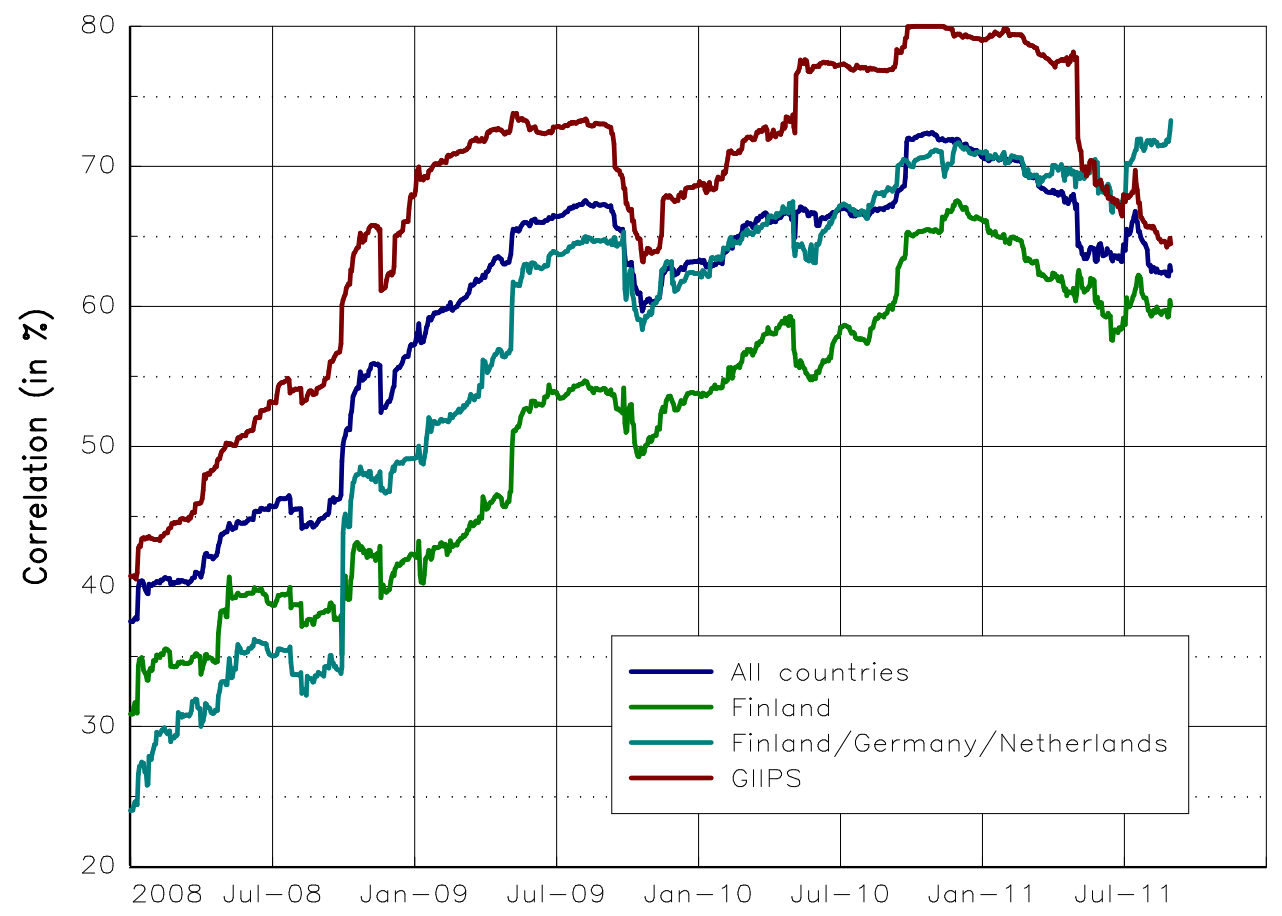


Table 2: Statistics of $\sigma_{i}^{S}$

\begin{tabular}{|c|c|c|c|c|c|}
\hline Country & July-08 & July-09 & July-10 & July-11 & September-11 \\
\hline Austria & $66.9 \%$ & $105.8 \%$ & $77.8 \%$ & $45.9 \%$ & $54.4 \%$ \\
Belgium & $73.3 \%$ & $88.9 \%$ & $78.0 \%$ & $57.2 \%$ & $65.8 \%$ \\
Finland & $106.8 \%$ & $97.9 \%$ & $75.2 \%$ & $49.8 \%$ & $55.7 \%$ \\
France & $78.2 \%$ & $91.8 \%$ & $97.7 \%$ & $57.3 \%$ & $63.9 \%$ \\
Germany & $81.3 \%$ & $98.5 \%$ & $74.9 \%$ & $48.8 \%$ & $55.7 \%$ \\
Greece & $67.5 \%$ & $65.8 \%$ & $94.7 \%$ & $49.4 \%$ & $56.8 \%$ \\
Ireland & $80.3 \%$ & $99.8 \%$ & $73.4 \%$ & $51.7 \%$ & $53.5 \%$ \\
Italy & $58.8 \%$ & $69.5 \%$ & $89.3 \%$ & $61.5 \%$ & $69.3 \%$ \\
Netherlands & $95.2 \%$ & $103.7 \%$ & $68.6 \%$ & $47.3 \%$ & $54.9 \%$ \\
Portugal & $66.9 \%$ & $72.0 \%$ & $116.6 \%$ & $53.5 \%$ & $58.3 \%$ \\
Spain & $72.4 \%$ & $76.8 \%$ & $90.2 \%$ & $58.9 \%$ & $64.6 \%$ \\
\hline
\end{tabular}

Table 3: Estimated $\Gamma$ matrix (January 2008)

\begin{tabular}{|c|c|c|c|c|c|c|c|c|c|c|c|}
\hline Country & AT & BE & $\mathrm{FI}$ & FR & $\mathrm{DE}$ & GR & IE & IT & $\mathrm{NL}$ & PT & ES \\
\hline Austria & $100 \%$ & & & & & & & & & & \\
\hline Belgium & $54 \%$ & $100 \%$ & & & & & & & & & \\
\hline Finland & $27 \%$ & $34 \%$ & $100 \%$ & & & & & & & & \\
\hline France & $55 \%$ & $60 \%$ & $42 \%$ & $100 \%$ & & & & & & & \\
\hline Germany & $51 \%$ & $43 \%$ & $23 \%$ & $50 \%$ & $100 \%$ & & & & & & \\
\hline Greece & $42 \%$ & $38 \%$ & $29 \%$ & $47 \%$ & $43 \%$ & $100 \%$ & & & & & \\
\hline Ireland & $33 \%$ & $35 \%$ & $41 \%$ & $37 \%$ & $27 \%$ & $22 \%$ & $100 \%$ & & & & \\
\hline Italy & $47 \%$ & $50 \%$ & $37 \%$ & $60 \%$ & $47 \%$ & $61 \%$ & $35 \%$ & $100 \%$ & & & \\
\hline Netherlands & $22 \%$ & $38 \%$ & $32 \%$ & $29 \%$ & $17 \%$ & $4 \%$ & $29 \%$ & $22 \%$ & $100 \%$ & & \\
\hline Portugal & $38 \%$ & $48 \%$ & $23 \%$ & $45 \%$ & $45 \%$ & $58 \%$ & $29 \%$ & $58 \%$ & $12 \%$ & $100 \%$ & \\
\hline Spain & $35 \%$ & $49 \%$ & $22 \%$ & $33 \%$ & $33 \%$ & $35 \%$ & $28 \%$ & $41 \%$ & $30 \%$ & $41 \%$ & $100 \%$ \\
\hline
\end{tabular}

Table 4: Estimated $\Gamma$ matrix (September 2011)

\begin{tabular}{|c|ccccccccccc|}
\hline Country & AT & BE & FI & FR & DE & GR & IE & IT & NL & PT & ES \\
\hline Austria & $100 \%$ & & & & & & & & & \\
Belgium & $75 \%$ & $100 \%$ & & & & & & & & \\
\hline Finland & $68 \%$ & $64 \%$ & $100 \%$ & & & & & & & \\
France & $72 \%$ & $70 \%$ & $61 \%$ & $100 \%$ & & & & & & \\
Germany & $77 \%$ & $72 \%$ & $65 \%$ & $72 \%$ & $100 \%$ & & & & & \\
Greece & $38 \%$ & $48 \%$ & $35 \%$ & $37 \%$ & $37 \%$ & $100 \%$ & & & & \\
Ireland & $58 \%$ & $62 \%$ & $55 \%$ & $56 \%$ & $59 \%$ & $54 \%$ & $100 \%$ & & & \\
Italy & $71 \%$ & $85 \%$ & $66 \%$ & $67 \%$ & $69 \%$ & $48 \%$ & $68 \%$ & $100 \%$ & & \\
Netherlands & $69 \%$ & $67 \%$ & $72 \%$ & $67 \%$ & $78 \%$ & $45 \%$ & $56 \%$ & $68 \%$ & $100 \%$ & \\
Portugal & $55 \%$ & $66 \%$ & $50 \%$ & $55 \%$ & $57 \%$ & $54 \%$ & $80 \%$ & $73 \%$ & $52 \%$ & $100 \%$ & \\
Spain & $67 \%$ & $76 \%$ & $56 \%$ & $60 \%$ & $61 \%$ & $49 \%$ & $69 \%$ & $80 \%$ & $56 \%$ & $71 \%$ & $100 \%$ \\
\hline
\end{tabular}




\subsection{Application to the EGBI portfolio}

Once these parameters are estimated, we can deduce for any sovereign bond portfolio the credit risk contribution of each country's debt. Using the previous formula to define $\mathcal{R}(x)$, we are able to compute the marginal credit-linked volatility and risk contribution, country by country ${ }^{9}$. The marginal risk expresses the impact of a small change in a country's index weight on the credit-linked volatility, whereas the risk contribution reflects the portion of the overall credit-linked volatility that a particular country is accountable for.

Let us consider the Citigroup EGBI index. Figure 3 shows the evolution of the credit risk contribution $(\mathrm{RC})$ of each country since the beginning of 2008 . We notice the increase of Greece's risk contribution since 2008. On April $27^{\text {th }} 2010$, the country's sovereign debt rating was cut to BB+ by Standard \& Poor's. Therefore Greece lost its investment grade status and exited the EGBI index at its next rebalancing date. The risk contribution of Greece reached a maximum of $28.5 \%$ on April $30^{\text {th }}, 2010$, while at the end of June 2010, just before its exit from the index, it remained very high, at $26 \%$. Since July 2010, we also notice an increase in the credit risk of Portugal, Ireland, Italy and Spain.

Figure 3: Evolution of risk contributions for the EGBI index

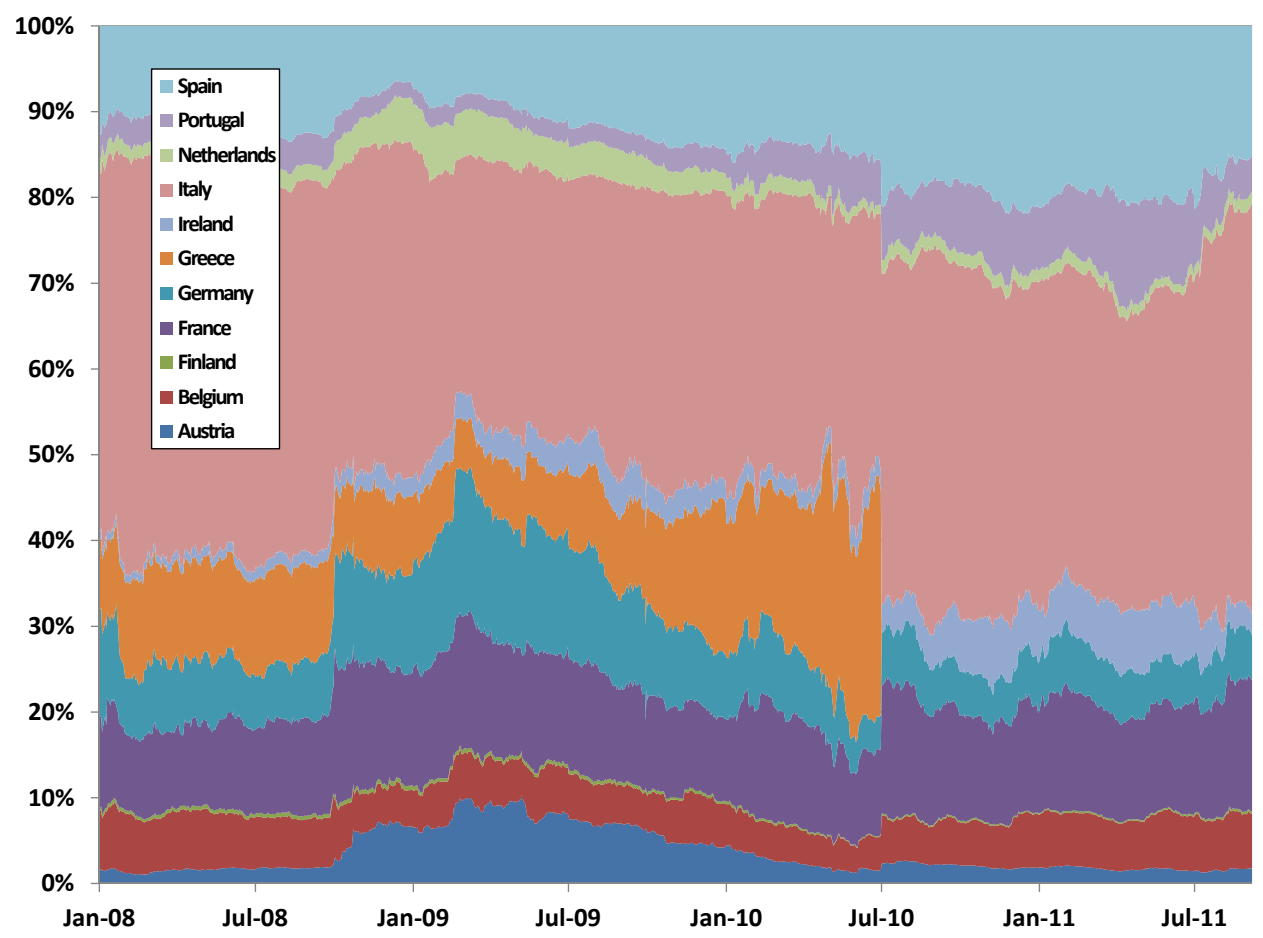

In Table 5 we report the weights and risk contributions for the constituents of the EGBI on some rebalancing dates. In July 2010 (after the exclusion of Greece) the Portugal, Ireland, Italy and Spain account for 35\% of the index weights, but $70 \%$ of the sovereign risk. In July 2011, these figures remain approximately the same ${ }^{10}$. The risk contribution of these four

\footnotetext{
${ }^{9}$ See Appendix A.2 for details.

${ }^{10}$ The weights decrease by $1 \%$ whereas the risk contributions increase by $3 \%$.
} 
Managing Sovereign Credit Risk in Bond Portfolios

Table 5: Weights and risk contributions of the EGBI index

\begin{tabular}{|c|c|c|c|c|c|c|c|c|c|c|}
\hline \multirow{2}{*}{ Country } & \multicolumn{2}{|c|}{ July-08 } & \multicolumn{2}{|c|}{ July-09 } & \multicolumn{2}{|c|}{ July-10 } & \multicolumn{2}{|c|}{ July-11 } & \multicolumn{2}{|c|}{ September-11 } \\
\hline & Weights & $\mathrm{RC}$ & Weights & $\mathrm{RC}$ & Weights & $\mathrm{RC}$ & Weights & $\mathrm{RC}$ & Weights & $\mathrm{RC}$ \\
\hline Austria & $4.1 \%$ & $1.7 \%$ & $3.6 \%$ & $7.7 \%$ & $4.1 \%$ & $2.3 \%$ & $4.3 \%$ & $1.5 \%$ & $4.3 \%$ & $1.8 \%$ \\
\hline Belgium & $6.2 \%$ & $6.1 \%$ & $6.5 \%$ & $5.1 \%$ & $6.3 \%$ & $5.7 \%$ & $6.4 \%$ & $6.5 \%$ & $6.4 \%$ & $6.7 \%$ \\
\hline Finland & $1.2 \%$ & $0.4 \%$ & $1.3 \%$ & $0.5 \%$ & $1.3 \%$ & $0.2 \%$ & $1.6 \%$ & $0.2 \%$ & $1.6 \%$ & $0.3 \%$ \\
\hline France & $20.5 \%$ & $9.8 \%$ & $20.4 \%$ & $13.2 \%$ & $22.2 \%$ & $15.1 \%$ & $23.1 \%$ & $13.3 \%$ & $23.1 \%$ & $15.5 \%$ \\
\hline Germany & $24.4 \%$ & $6.1 \%$ & $22.3 \%$ & $13.0 \%$ & $22.9 \%$ & $6.0 \%$ & $22.1 \%$ & $5.3 \%$ & $22.1 \%$ & $5.5 \%$ \\
\hline Greece & $4.9 \%$ & $11.4 \%$ & $5.4 \%$ & $8.5 \%$ & $0.0 \%$ & $0.0 \%$ & $0.0 \%$ & $0.0 \%$ & $0.0 \%$ & $0.0 \%$ \\
\hline Ireland & $1.0 \%$ & $1.3 \%$ & $1.5 \%$ & $4.3 \%$ & $2.1 \%$ & $3.3 \%$ & $1.4 \%$ & $5.4 \%$ & $1.4 \%$ & $2.7 \%$ \\
\hline Italy & $22.1 \%$ & $45.2 \%$ & $22.4 \%$ & $29.5 \%$ & $23.4 \%$ & $38.7 \%$ & $23.1 \%$ & $38.5 \%$ & $23.1 \%$ & $46.3 \%$ \\
\hline Netherlands & $5.3 \%$ & $1.7 \%$ & $5.3 \%$ & $4.1 \%$ & $6.1 \%$ & $1.6 \%$ & $6.2 \%$ & $1.2 \%$ & $6.2 \%$ & $1.5 \%$ \\
\hline Portugal & $2.4 \%$ & $3.9 \%$ & $2.3 \%$ & $2.3 \%$ & $2.1 \%$ & $6.3 \%$ & $1.6 \%$ & $6.6 \%$ & $1.6 \%$ & $4.4 \%$ \\
\hline Spain & $7.8 \%$ & $12.4 \%$ & $9.1 \%$ & $11.8 \%$ & $9.6 \%$ & $20.9 \%$ & $10.3 \%$ & $21.3 \%$ & $10.3 \%$ & $15.5 \%$ \\
\hline $\begin{array}{c}\text { Sovereign } \\
\text { Risk }\end{array}$ & \multicolumn{2}{|c|}{$0.70 \%$} & \multicolumn{2}{|c|}{$2.59 \%$} & \multicolumn{2}{|c|}{$6.12 \%$} & \multicolumn{2}{|c|}{$4.02 \%$} & \multicolumn{2}{|c|}{$8.12 \%$} \\
\hline
\end{tabular}

countries is therefore very high, although smaller than the $83 \%$ reached during the peak of May 2011. By contrast, in February 2009 their collective risk contribution was only $46 \%{ }^{11}$.

\section{Implications for the management of bond portfolios}

Capitalisation-weighted indices presenting clear drawbacks, we propose an alternative approach to indexation, based on sovereign risk. Using the framework described previously, it is possible to decompose the risk of a sovereign bond portfolio into individual country contributions. Given the portfolio weights, we can find the risk contributions. Risk budgeting is basically the same process in reverse. Given a set of defined risk contributions, risk budgeting provides a portfolio allocation. The problem with traditional indices is that investors may face a high level of risk concentration. To avoid that, investors can start by defining a set of risk budgets that they find appropriate and then derive the corresponding weights. Even if the risk budgets are fixed, the portfolio weights still vary over time as the risk associated with each country fluctuates. This way, when an individual country's situation deteriorates, this is reflected in its spread and thereby its risk, leading eventually to a reduction of its weight. Risk budgeting thus allows investors to control the distribution of risk over time. However, it does not address the problem of how to choose the right risk budgets.

\subsection{Fundamental indexation}

The GDP weighting approach can help us to define the risk budgets. Toloui (2010) writes:

"An alternative to market-cap weighting is to weight country exposures in global bond indexes by GDP instead of market capitalisation. [...] In contrast to market-cap weighting, GDP weighting does not reward countries with high levels of debt issuance: Countries with higher debt-to-GDP levels generally have a lower representation in a GDP-weighted index versus a market- cap-weighted index."

\footnotetext{
${ }^{11}$ The decomposition was $5.8 \%$ for Greece, $3.0 \%$ for Ireland, $27.1 \%$ for Italy, $1.9 \%$ for Portugal and $8.3 \%$ for Spain.
} 
Managing Sovereign Credit Risk in Bond Portfolios

Table 6: Weights and risk contributions of the GDP indexation

\begin{tabular}{|c|c|c|c|c|c|c|c|c|c|c|}
\hline \multirow{2}{*}{ Country } & \multicolumn{2}{|c|}{ July-08 } & \multicolumn{2}{|c|}{ July-09 } & \multicolumn{2}{|c|}{ July-10 } & \multicolumn{2}{|c|}{ July-11 } & \multicolumn{2}{|c|}{ September-11 } \\
\hline & GDP & $\mathrm{RC}$ & GDP & $\mathrm{RC}$ & GDP & $\mathrm{RC}$ & GDP & $\mathrm{RC}$ & GDP & $\mathrm{RC}$ \\
\hline Austria & $3.1 \%$ & $1.4 \%$ & $3.1 \%$ & $7.0 \%$ & $3.1 \%$ & $1.7 \%$ & $3.2 \%$ & $1.0 \%$ & $3.2 \%$ & $1.3 \%$ \\
\hline Belgium & $3.8 \%$ & $4.0 \%$ & $3.8 \%$ & $3.2 \%$ & $3.9 \%$ & $3.3 \%$ & $4.0 \%$ & $3.5 \%$ & $4.0 \%$ & $4.0 \%$ \\
\hline Finland & $2.0 \%$ & $0.8 \%$ & $1.9 \%$ & $0.7 \%$ & $2.0 \%$ & $0.3 \%$ & $2.1 \%$ & $0.3 \%$ & $2.1 \%$ & $0.3 \%$ \\
\hline France & $21.2 \%$ & $11.2 \%$ & $21.5 \%$ & $14.9 \%$ & $21.4 \%$ & $13.4 \%$ & $21.5 \%$ & $10.6 \%$ & $21.5 \%$ & $13.8 \%$ \\
\hline Germany & $27.4 \%$ & $7.6 \%$ & $27.2 \%$ & $17.0 \%$ & $27.7 \%$ & $6.7 \%$ & $27.9 \%$ & $5.8 \%$ & $27.9 \%$ & $6.7 \%$ \\
\hline Greece & $2.6 \%$ & $6.2 \%$ & $2.7 \%$ & $4.4 \%$ & $2.6 \%$ & $15.7 \%$ & $2.4 \%$ & $19.8 \%$ & $2.4 \%$ & $13.8 \%$ \\
\hline Ireland & $2.0 \%$ & $3.0 \%$ & $1.9 \%$ & $5.6 \%$ & $1.8 \%$ & $2.6 \%$ & $1.7 \%$ & $5.9 \%$ & $1.7 \%$ & $3.3 \%$ \\
\hline Italy & $17.4 \%$ & $37.5 \%$ & $17.3 \%$ & $23.5 \%$ & $17.2 \%$ & $25.8 \%$ & $17.0 \%$ & $23.9 \%$ & $17.0 \%$ & $32.6 \%$ \\
\hline Netherlands & $6.5 \%$ & $2.5 \%$ & $6.5 \%$ & $5.3 \%$ & $6.5 \%$ & $1.6 \%$ & $6.6 \%$ & $1.2 \%$ & $6.6 \%$ & $1.6 \%$ \\
\hline Portugal & $1.9 \%$ & $3.3 \%$ & $1.9 \%$ & $2.0 \%$ & $1.9 \%$ & $5.3 \%$ & $1.9 \%$ & $6.7 \%$ & $1.9 \%$ & $5.1 \%$ \\
\hline Spain & $12.0 \%$ & $22.6 \%$ & $12.0 \%$ & $16.5 \%$ & $11.8 \%$ & $23.7 \%$ & $11.8 \%$ & $21.4 \%$ & $11.8 \%$ & $17.5 \%$ \\
\hline $\begin{array}{c}\text { Sovereign } \\
\text { Risk }\end{array}$ & \multicolumn{2}{|c|}{$0.64 \%$} & \multicolumn{2}{|c|}{$2.47 \%$} & \multicolumn{2}{|c|}{$6.59 \%$} & \multicolumn{2}{|c|}{$4.56 \%$} & \multicolumn{2}{|c|}{$8.26 \%$} \\
\hline
\end{tabular}

In our opinion, the GDP weighting approach is a first step towards avoiding the "buy high, sell low" problem of capitalisation weighting. A direct extension of this approach is to consider the GDP-RB (risk budgeting) weighting approach. In this case, the weights are computed such that the risk contribution of each country is proportional to its GDP. Using GDP as the basis for a risk budget allows us to consider GDP weighting schemes as a special case of GDP-RB weighting approach (in other words, GDP weighting implies that all countries present the same risk levels and correlations).

Let us now consider the eleven national sub-indices of the Citigroup EGBI index. Each sub-index can be seen as a proxy of the relevant country's outstanding debt and will be treated as if it were a bond. A GDP weighting approach consists in fixing at each rebalancing date the weight of the $i^{\text {th }}$ country in the portfolio as equal to the share of its GDP in the total GDP of the Eurozone:

$$
x_{i}=\frac{\mathrm{GDP}_{i}}{\sum_{j=1}^{11} \mathrm{GDP}_{j}}
$$

In Table 6 and Figure 4 we use a GDP weighting scheme ${ }^{12}$. Under GDP-based indexation Greece has a smaller index allocation than under capitalisation weighting. For example, in July 2008, the weight of Greece was $4.91 \%$ by market capitalisation (Table 5 ) but only $2.61 \%$ under GDP-based indexation (Table 6 ). We observe the same phenomenon for Italy and Portugal. Nevertheless, we notice that this type of indexation increases the weight of Spain or Ireland. This is because the debt to GDP ratio is lower than average for these countries. We remark that GDP indexation produces a more balanced portfolio in terms of risk than debt-based indexation, but that risk is still concentrated in a few countries.

Another disappointing result is that GDP indexation produces sovereign credit risk measures similar to those of DEBT indexation. For example, the sovereign risk measure is equal to $8.26 \%$ for the GDP indexation in September 2011 which is close to the $8.12 \%$ obtained with the EGBI portfolio.

\footnotetext{
${ }^{12}$ The GDP column may also be viewed as the weights of the bond portfolio.
} 
Figure 4: Evolution of risk contributions for the GDP indexation

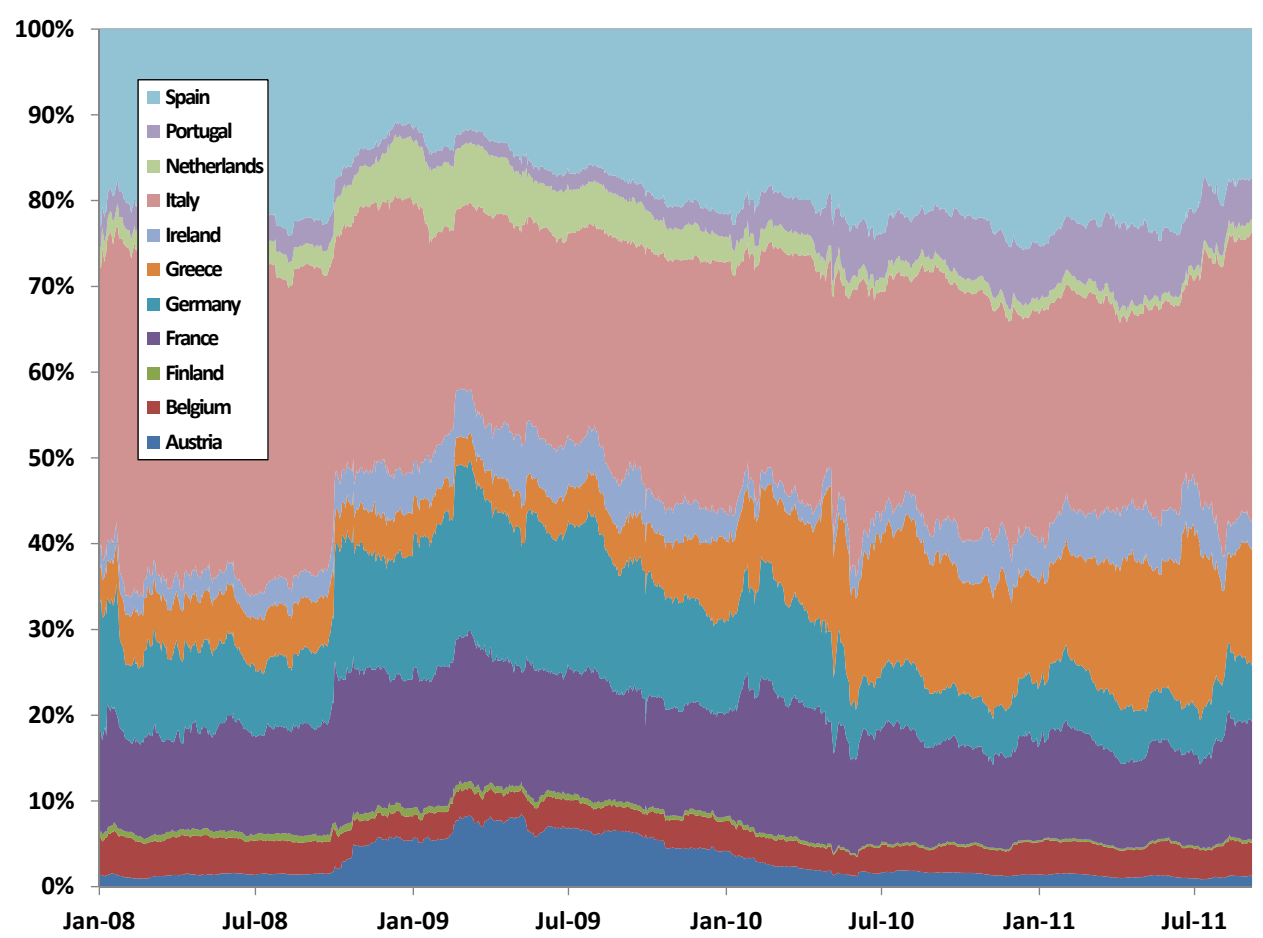

\subsection{Risk-based indexation}

Risk-based indexation is more difficult to define for bond portfolios than for equity portfolios. For the later, a lot of allocation methods exist and are adapted to define a risk-based portfolio ${ }^{13}$. These methods, however, are not suited for bond portfolios ${ }^{14}$ except for the risk budgeting techniques that prove appropriate.

\subsubsection{An introduction to risk budgeting allocation methods}

The risk budgeting method is explained in Meucci (2005) and Sherer (2007). This technique makes it possible to control the risk allocated to each constituents of a portfolio. Let $x=$ $\left(x_{1}, \ldots, x_{n}\right)$ be the portfolio weights. If we use a coherent convex risk measure $\mathcal{R}\left(x_{1}, \ldots, x_{n}\right)$, we have :

$$
\mathcal{R}\left(x_{1}, \ldots, x_{n}\right)=\sum_{i=1}^{n} \operatorname{RC}_{i}\left(x_{1}, \ldots, x_{n}\right)
$$

where $\mathrm{RC}_{i}\left(x_{1}, \ldots, x_{n}\right)$ is the risk contribution of the $i^{\text {th }}$ asset :

$$
\mathrm{RC}_{i}\left(x_{1}, \ldots, x_{n}\right)=x_{i} \cdot \frac{\partial \mathcal{R}\left(x_{1}, \ldots, x_{n}\right)}{\partial x_{i}}
$$

\footnotetext{
${ }^{13}$ We can cite for example the equally-weighted portfolio (DeMiguel et al., 2009), the minimum variance portfolio (Clarke et al., 2006), the erc portfolio (Maillard et al., 2010) or the mdp/msr portfolio (Choueifaty and Coignard, 2008 and Martellini, 2008).

${ }^{14}$ Moreover, some of these methods face some concentration problems (Roncalli, 2011). For example, if we consider the minimum variance portfolio, we will obtained a very concentrated portfolio in Finland and Germany.
} 
Table 7: Comparison of traditional and risk budgeting approaches

\begin{tabular}{|c|c|c|cc|}
\hline \multicolumn{5}{|c|}{ Traditional approach } \\
\hline \multirow{2}{*}{ Asset } & \multirow{2}{*}{ Weight } & Marginal & \multicolumn{2}{c|}{ Risk Contribution } \\
& & Risk & Absolute & Relative \\
\hline 1 & $60.00 \%$ & $18.80 \%$ & $11.28 \%$ & $66.67 \%$ \\
2 & $20.00 \%$ & $23.94 \%$ & $4.79 \%$ & $28.30 \%$ \\
3 & $20.00 \%$ & $4.26 \%$ & $0.85 \%$ & $5.03 \%$ \\
\hline Volatility
\end{tabular}

Risk budgeting approach

\begin{tabular}{|c|c|c|cc|}
\hline \multirow{2}{*}{ Asset } & \multirow{2}{*}{ Weight } & Marginal & \multicolumn{2}{|c|}{ Risk Contribution } \\
& & Risk & Absolute & Relative \\
\hline 1 & $48.50 \%$ & $17.69 \%$ & $8.58 \%$ & $60.00 \%$ \\
2 & $13.17 \%$ & $21.71 \%$ & $2.86 \%$ & $20.00 \%$ \\
3 & $38.32 \%$ & $7.46 \%$ & $2.86 \%$ & $20.00 \%$ \\
\hline Volatility & \multicolumn{4}{|c}{$14.30 \%$} \\
\hline
\end{tabular}

To define a risk budgeting (or $\mathrm{RB}$ ) portfolio, we consider a set of given risk budgets $\left\{\mathrm{RB}_{1}, \ldots, \mathrm{RB}_{n}\right\}$. Then we have to solve the following non-linear system of $n$ equations ${ }^{15}$ :

$$
\left\{\begin{array}{c}
\mathrm{RC}_{1}\left(x_{1}, \ldots, x_{n}\right)=\mathrm{RB}_{1} \\
\vdots \\
\mathrm{RC}_{n}\left(x_{1}, \ldots, x_{n}\right)=\mathrm{RB}_{n}
\end{array}\right.
$$

Remark 1 The philosophy of the risk budgeting approach is then the opposite of the traditional approach. In the traditional approach, the weights of the portfolio are given and we determine the risk contributions according to these weights. Conversely, in the risk budgeting approach, the risk contributions of the portfolio are given and we determine the weights according to these risk contributions. To illustrate these differences, we consider three assets. The volatilities are respectively $20 \%, 30 \%$ and $15 \%$. The correlations are $60 \%$ between the first asset and the second asset and $10 \%$ between the first two assets and the third asset. We assume that the risk measure is the volatility of the portfolio. In Table 7, we report the volatility decomposition of the portfolio with weights $60 \%, 20 \%$ and $20 \%$. We notice that the third asset has a weight contribution of $20 \%$ but a risk contribution of only $5 \%$. If we now consider a portfolio such that the risk budgets are $60 \%, 20 \%$ and $20 \%$, the weights are $48.5 \%, 13.2 \%$ and $38.3 \%$. This means that we must set the third asset weight to $38.3 \%$ if we want it to account for $20 \%$ of the portfolio risk.

\subsubsection{The GDP-RB indexation}

For the GDP-RB approach, we have to estimate the vector of weights such that the risk contribution of the $i^{\text {th }}$ country is equal to the part of its GDP in the total GDP of the Eurozone:

$$
\mathrm{RC}_{i}=\frac{\mathrm{GDP}_{i}}{\sum_{j=1}^{11} \mathrm{GDP}_{j}}
$$

The solution is shown in Figure 5 and in Table 8. By construction, the risk contributions of GDP-RB indexation correspond to the weights of GDP indexation. For example, in July 2008, Austria had a $3.1 \%$ weight in the GDP indexed portfolio, the same as its $3.1 \%$

\footnotetext{
${ }^{15}$ The numerical solution may be obtained by using non-linear optimisation procedures like the sequential quadratic programming (SQP) algorithm.
} 
Figure 5: Evolution of weights of the GDP-RB indexation

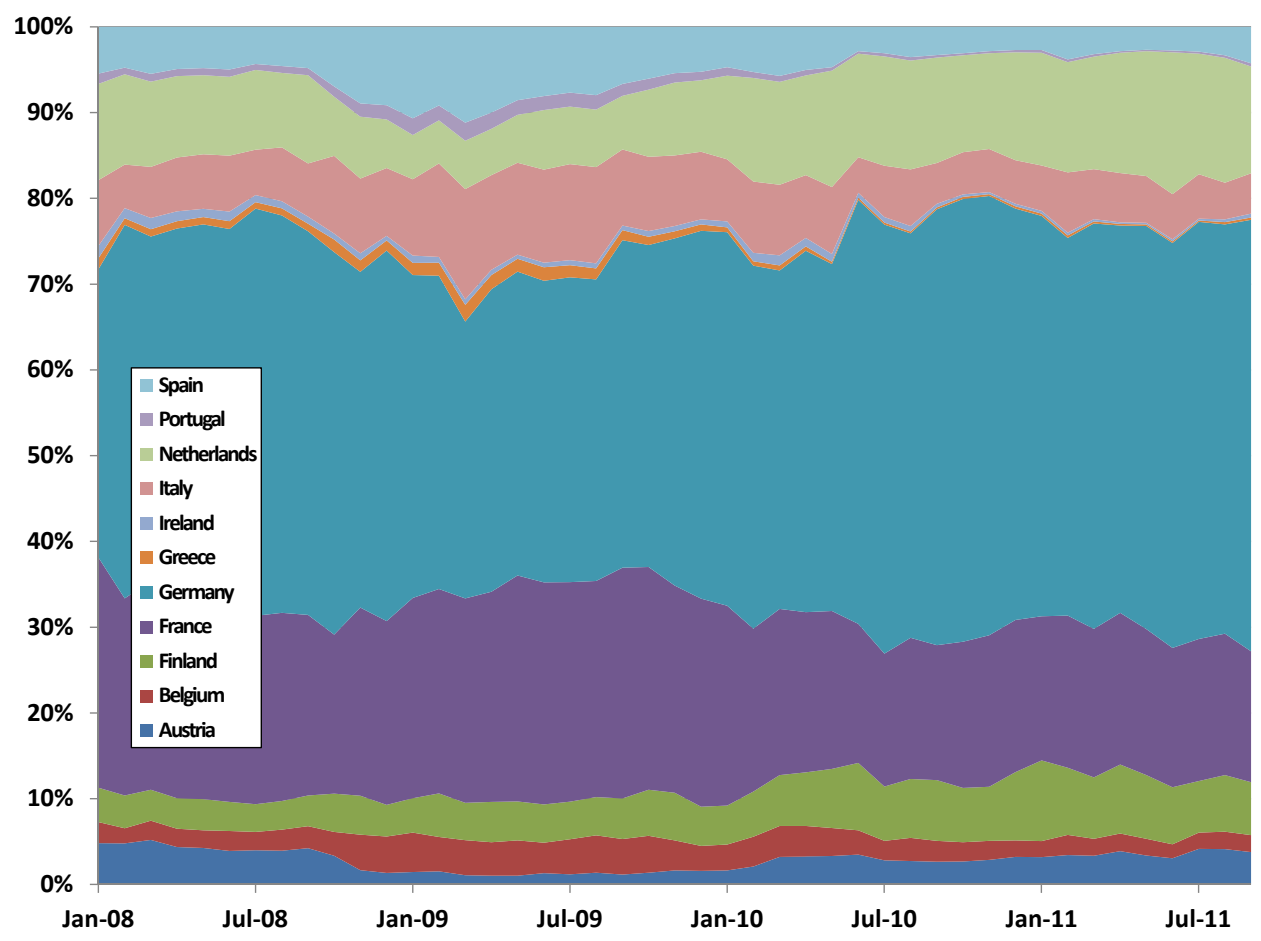

Table 8: Weights and risk contributions of the GDP-RB indexation

\begin{tabular}{|c|c|c|c|c|c|c|c|c|c|c|}
\hline \multirow{2}{*}{ Country } & \multicolumn{2}{|c|}{ July-08 } & \multicolumn{2}{|c|}{ July-09 } & \multicolumn{2}{|c|}{ July-10 } & \multicolumn{2}{|c|}{ July-11 } & \multicolumn{2}{|c|}{ September-11 } \\
\hline & $\mathrm{RC}$ & Weights & $\mathrm{RC}$ & Weights & $\mathrm{RC}$ & Weights & $\mathrm{RC}$ & Weights & $\mathrm{RC}$ & Weights \\
\hline Austria & $3.1 \%$ & $3.9 \%$ & $3.1 \%$ & $1.2 \%$ & $3.1 \%$ & $2.9 \%$ & $3.2 \%$ & $4.2 \%$ & $3.2 \%$ & $3.8 \%$ \\
\hline Belgium & $3.8 \%$ & $2.1 \%$ & $3.8 \%$ & $4.1 \%$ & $3.9 \%$ & $2.2 \%$ & $4.0 \%$ & $1.9 \%$ & $4.0 \%$ & $2.0 \%$ \\
\hline Finland & $2.0 \%$ & $3.2 \%$ & $1.9 \%$ & $4.4 \%$ & $2.0 \%$ & $6.3 \%$ & $2.1 \%$ & $6.0 \%$ & $2.1 \%$ & $6.1 \%$ \\
\hline France & $21.2 \%$ & $22.0 \%$ & $21.5 \%$ & $25.6 \%$ & $21.4 \%$ & $15.5 \%$ & $21.5 \%$ & $16.5 \%$ & $21.5 \%$ & $15.3 \%$ \\
\hline Germany & $27.4 \%$ & $47.8 \%$ & $27.2 \%$ & $35.5 \%$ & $27.7 \%$ & $50.0 \%$ & $27.9 \%$ & $48.7 \%$ & $27.9 \%$ & $50.2 \%$ \\
\hline Greece & $2.6 \%$ & $0.7 \%$ & $2.7 \%$ & $1.4 \%$ & $2.6 \%$ & $0.2 \%$ & $2.4 \%$ & $0.2 \%$ & $2.4 \%$ & $0.3 \%$ \\
\hline Ireland & $2.0 \%$ & $0.8 \%$ & $1.9 \%$ & $0.6 \%$ & $1.8 \%$ & $0.6 \%$ & $1.7 \%$ & $0.2 \%$ & $1.7 \%$ & $0.5 \%$ \\
\hline Italy & $17.4 \%$ & $5.3 \%$ & $17.3 \%$ & $11.2 \%$ & $17.2 \%$ & $6.0 \%$ & $17.0 \%$ & $5.2 \%$ & $17.0 \%$ & $4.7 \%$ \\
\hline Netherlands & $6.5 \%$ & $9.2 \%$ & $6.5 \%$ & $6.7 \%$ & $6.5 \%$ & $12.8 \%$ & $6.6 \%$ & $14.0 \%$ & $6.6 \%$ & $12.5 \%$ \\
\hline Portugal & $1.9 \%$ & $0.7 \%$ & $1.9 \%$ & $1.6 \%$ & $1.9 \%$ & $0.4 \%$ & $1.9 \%$ & $0.2 \%$ & $1.9 \%$ & $0.4 \%$ \\
\hline Spain & $12.0 \%$ & $4.2 \%$ & $12.0 \%$ & $7.7 \%$ & $11.8 \%$ & $3.1 \%$ & $11.8 \%$ & $2.9 \%$ & $11.8 \%$ & $4.2 \%$ \\
\hline $\begin{array}{l}\text { Sovereign } \\
\text { Risk }\end{array}$ & \multicolumn{2}{|c|}{$0.39 \%$} & \multicolumn{2}{|c|}{$2.10 \%$} & \multicolumn{2}{|c|}{$3.25 \%$} & \multicolumn{2}{|c|}{$1.91 \%$} & \multicolumn{2}{|c|}{$4.13 \%$} \\
\hline
\end{tabular}


Figure 6: Evolution of weights of the DEBT-RB indexation

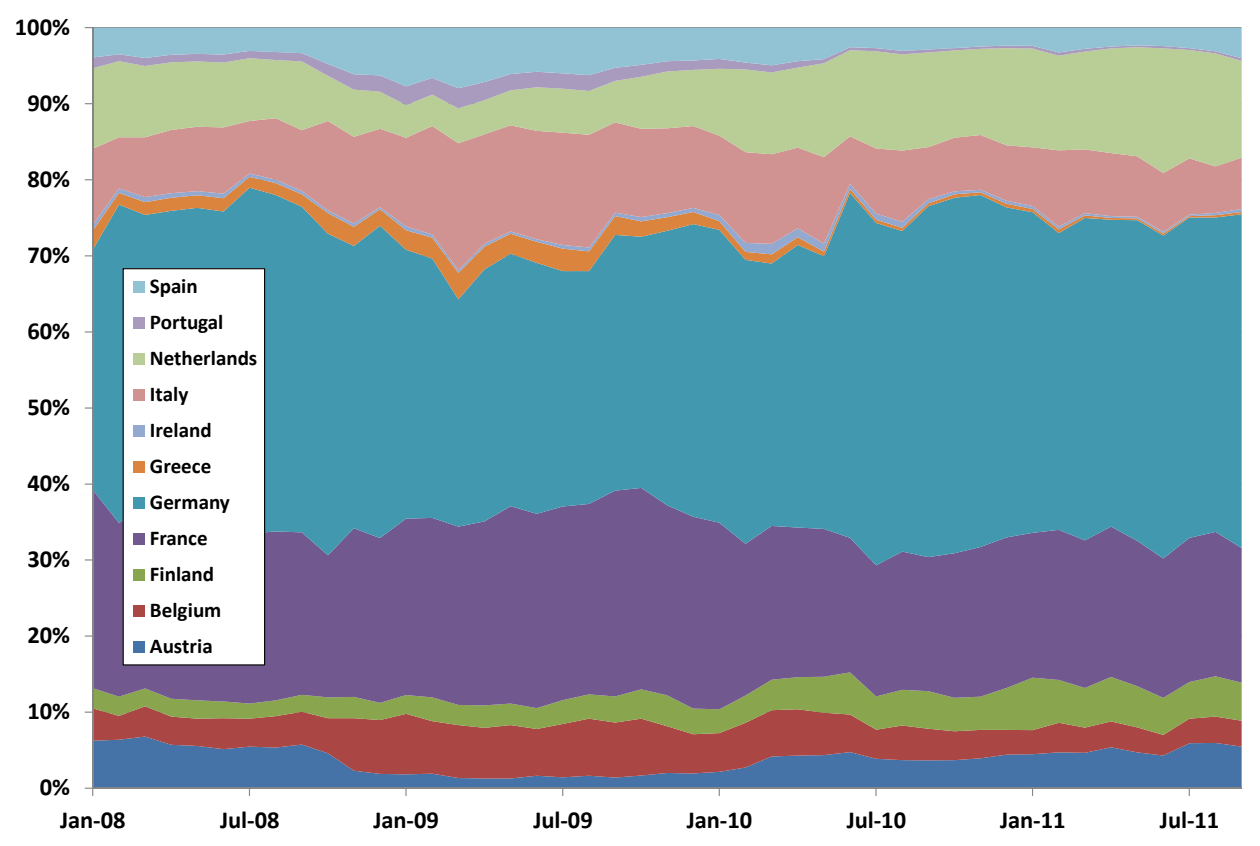

risk contribution in the portfolio based on GDP-RB indexation. In Table 8, we clearly see the impact of the sovereign credit risk of individual countries. For example, the weight of Germany is lower under GDP indexation than under GDP-RB indexation. The same phenomenon appears for other "safe" countries like Finland or the Netherlands. We also notice that the portfolio structure varies a lot across time, depending on the sovereign risk priced in by the market. The GDP-RB portfolio is further away from the GDP portfolio in periods of risk aversion, such as July 2011, whereas it is closer when sovereign risk concerns are relatively low, as in July 2009. Moreover, we notice that the GDP-RB indexation has a lower sovereign risk measure compared to DEBT or GDP indexations. For example, at the $1^{\text {st }}$ September 2011, it is equal to $4.13 \%$ for the GDP-RB indexation whereas it is equal to $8.12 \%$ and $8.26 \%$ for the DEBT or GDP indexations.

\subsubsection{The DEBT-RB indexation}

This methodology may be applied to other metrics than GDP. For example, if we consider the amount of debt (DEBT), the portfolio is built such that:

$$
\mathrm{RC}_{i}=\frac{\mathrm{DEBT}_{i}}{\sum_{j=1}^{11} \mathrm{DEBT}_{j}}
$$

This case is illustrated in Figure 6 and Table 9. One interesting property of the risk budgeting approach is that when sovereign risk is the same for all countries, the solution corresponds to the weights of the traditional benchmark. In the case of the DEBT-RB approach, assuming equal risks gives us the weights of the capitalisation-weighting scheme (i.e. the DEBTweighting scheme). 
Managing Sovereign Credit Risk in Bond Portfolios

Table 9: Weights and risk contributions of the DEBT-RB indexation

\begin{tabular}{|c|cc|cc|cc|cc|cc|}
\hline \multirow{2}{*}{ Country } & \multicolumn{2}{|c|}{ July-08 } & \multicolumn{2}{c|}{ July-09 } & \multicolumn{2}{c|}{ July-10 } & \multicolumn{2}{c|}{ July-11 } & \multicolumn{2}{c|}{ September-11 } \\
& RC & Weights & RC & Weights & RC & Weights & RC & Weights & RC & Weights \\
\hline Austria & $4.1 \%$ & $5.4 \%$ & $3.6 \%$ & $1.4 \%$ & $3.9 \%$ & $3.9 \%$ & $4.2 \%$ & $5.9 \%$ & $4.2 \%$ & $5.5 \%$ \\
Belgium & $6.2 \%$ & $3.6 \%$ & $6.5 \%$ & $7.1 \%$ & $6.0 \%$ & $3.8 \%$ & $6.2 \%$ & $3.2 \%$ & $6.2 \%$ & $3.4 \%$ \\
Finland & $1.2 \%$ & $2.0 \%$ & $1.3 \%$ & $3.1 \%$ & $1.2 \%$ & $4.4 \%$ & $1.5 \%$ & $4.8 \%$ & $1.5 \%$ & $5.0 \%$ \\
France & $20.5 \%$ & $22.4 \%$ & $20.4 \%$ & $25.5 \%$ & $21.2 \%$ & $17.2 \%$ & $22.5 \%$ & $18.9 \%$ & $22.5 \%$ & $17.7 \%$ \\
Germany & $24.4 \%$ & $45.8 \%$ & $22.3 \%$ & $30.9 \%$ & $21.9 \%$ & $45.0 \%$ & $21.5 \%$ & $42.1 \%$ & $21.5 \%$ & $43.9 \%$ \\
Greece & $4.9 \%$ & $1.4 \%$ & $5.4 \%$ & $2.9 \%$ & $4.3 \%$ & $0.4 \%$ & $2.6 \%$ & $0.2 \%$ & $2.5 \%$ & $0.3 \%$ \\
Ireland & $1.0 \%$ & $0.4 \%$ & $1.5 \%$ & $0.5 \%$ & $2.0 \%$ & $0.8 \%$ & $1.4 \%$ & $0.2 \%$ & $1.4 \%$ & $0.4 \%$ \\
Italy & $22.1 \%$ & $6.9 \%$ & $22.4 \%$ & $14.8 \%$ & $22.4 \%$ & $8.5 \%$ & $22.5 \%$ & $7.4 \%$ & $22.5 \%$ & $6.7 \%$ \\
Netherlands & $5.3 \%$ & $8.2 \%$ & $5.3 \%$ & $5.8 \%$ & $5.9 \%$ & $12.8 \%$ & $6.0 \%$ & $14.3 \%$ & $6.0 \%$ & $12.7 \%$ \\
Portugal & $2.4 \%$ & $0.9 \%$ & $2.3 \%$ & $2.0 \%$ & $2.0 \%$ & $0.4 \%$ & $1.6 \%$ & $0.2 \%$ & $1.6 \%$ & $0.4 \%$ \\
Spain & $7.8 \%$ & $3.0 \%$ & $9.1 \%$ & $6.0 \%$ & $9.2 \%$ & $2.7 \%$ & $10.1 \%$ & $2.7 \%$ & $10.1 \%$ & $4.0 \%$ \\
\hline Sovereign & \multirow{2}{*}{$0.41 \%$} & \multicolumn{2}{|c|}{$2.19 \%$} & & $2.63 \%$ & & $2.10 \%$ & & $4.57 \%$ \\
Risk & & & & & & & & & & \\
\hline
\end{tabular}

\section{Comparison of the indexing schemes}

We may now simulate the four indexing approaches: DEBT-weighting, GDP-weighting, GDP-based risk budgeting and DEBT-based risk budgeting ${ }^{16}$. In what follows, we compare all these weighting schemes in terms of performance, risk and portfolio characteristics.

\subsection{In terms of performance}

The results are given in Figure 7 and relevant statistics are shown in Table 10. We notice that alternative index approaches to capitalisation weighting post better performances. We notice that risk-based indexations yield the best returns but generate higher tracking errors. Of course, these results depend on the study period and may be explained by the economic situation since 2008 .

Table 10: Main statistics (01/01/2008 - 06/09/2011)

\begin{tabular}{|c|c|c|c|c|c|c|}
\cline { 2 - 7 } \multicolumn{1}{c|}{} & DEBT & GDP & GDP-RB & DEBT-RB & DEBT* & DEBT*-RB \\
\hline Average Return & $4.7 \%$ & $5.2 \%$ & $6.8 \%$ & $6.5 \%$ & $4.8 \%$ & $6.6 \%$ \\
Volatility & $4.4 \%$ & $4.3 \%$ & $4.4 \%$ & $4.4 \%$ & $4.4 \%$ & $4.4 \%$ \\
Sharpe & 1.05 & 1.19 & 1.53 & 1.49 & 1.10 & 1.50 \\
Tracking Error & & $0.6 \%$ & $2.2 \%$ & $2.0 \%$ & $0.3 \%$ & $2.0 \%$ \\
Information Ratio & & 0.84 & 0.91 & 0.90 & 0.55 & 0.91 \\
Correlation & & $99.2 \%$ & $87.4 \%$ & $89.7 \%$ & $99.8 \%$ & $89.6 \%$ \\
Beta & & $97.1 \%$ & $87.5 \%$ & $88.8 \%$ & $98.9 \%$ & $88.7 \%$ \\
\hline
\end{tabular}

\footnotetext{
${ }^{16}$ In the DEBT* case, we have excluded Greece since July 2010 in order to be coherent with the construction of the EGBI portfolio.
} 
Figure 7: Simulation of the performance of the 4 indexing schemes

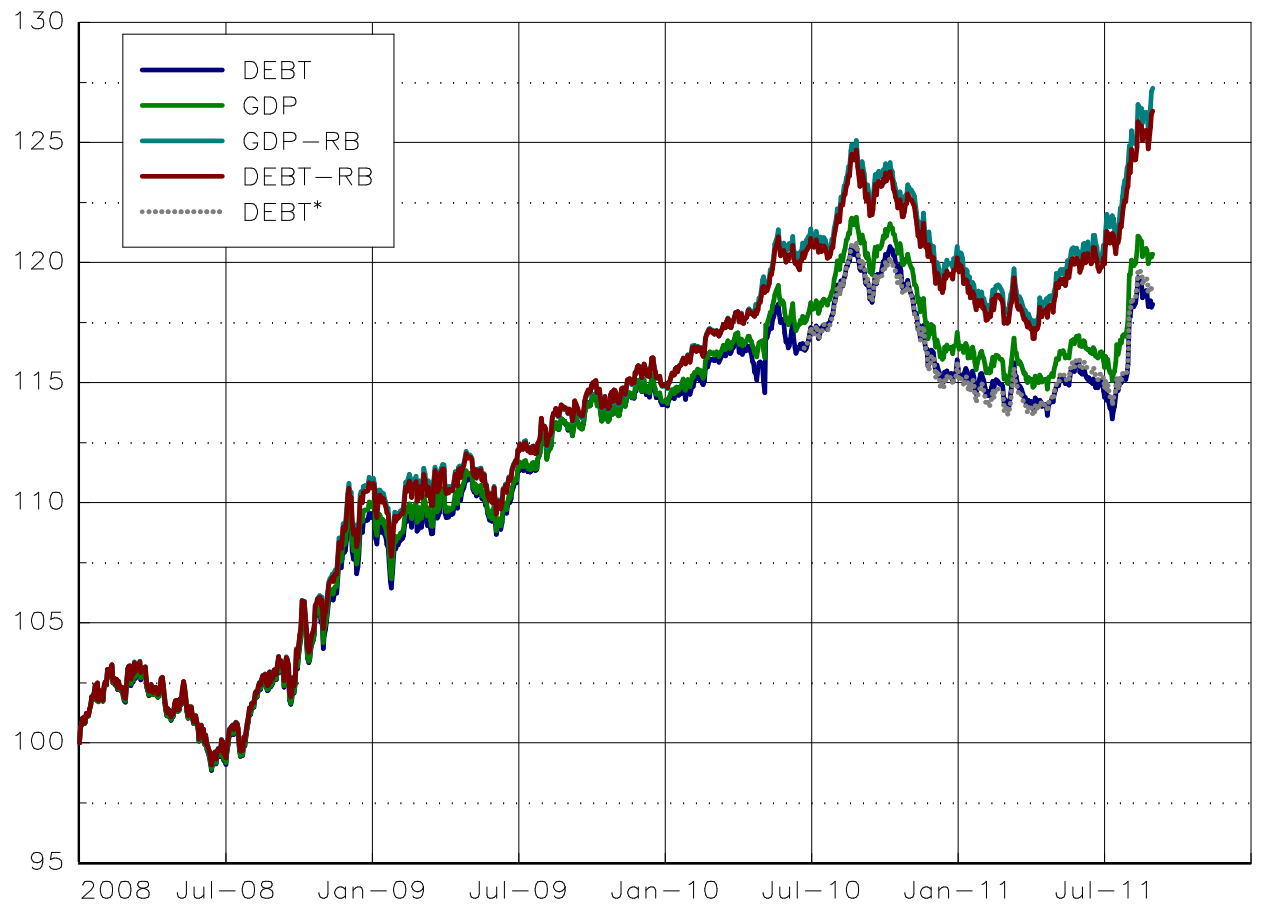

\subsection{In terms of risk}

Our purpose here is not to say that alternative indexations are better than capitalisation weighting. Having said that, the fact that only alternative methodologies can integrate a sovereign risk dimension is an undeniable asset ${ }^{17}$. In the risk budgeting approaches, it is easy to see how it is implemented and what benefits can be expected. Evolution of the sovereign risk measure is reported in Figure 8 for the 4 indexation schemes. As expected, we find that risk-based indexations present lower sovereign risk. If we compare the risk contribution of GIIPS countries, we observe a difference between risk-based indexation on the one hand, and capitalisation and fundamental indexation on the other hand (see Figure $9)$.

\subsection{In terms of portfolio characteristics}

In Table 11, we report the weights and risk contributions and some other statistics like yield-to-maturity, duration and average spread as at the beginning of September 2011. We also compute the concentration measure given by the Gini index. This statistic takes the value 1 in case of perfect concentration and 0 if no concentration exists. The Gini coefficient is applied both to weights and to risk contributions. When considering weights, the less concentrated portfolio (with a Gini index equal to 0) corresponds to the equally weighted portfolio, whereas the less concentrated portfolio in terms of risk corresponds to the equal risk contributions (ERC) portfolio (Maillard et al., 2010). In both cases, the most concentrated

\footnotetext{
${ }^{17}$ In some sense, GDP, GDP-RB and DEBT-RB may be viewed as the equivalent for bonds of the existing schemes of fundamental and risk-based indexation for equities (Demey et al., 2010).
} 
Figure 8: Evolution of the risk measure for the 4 indexing schemes

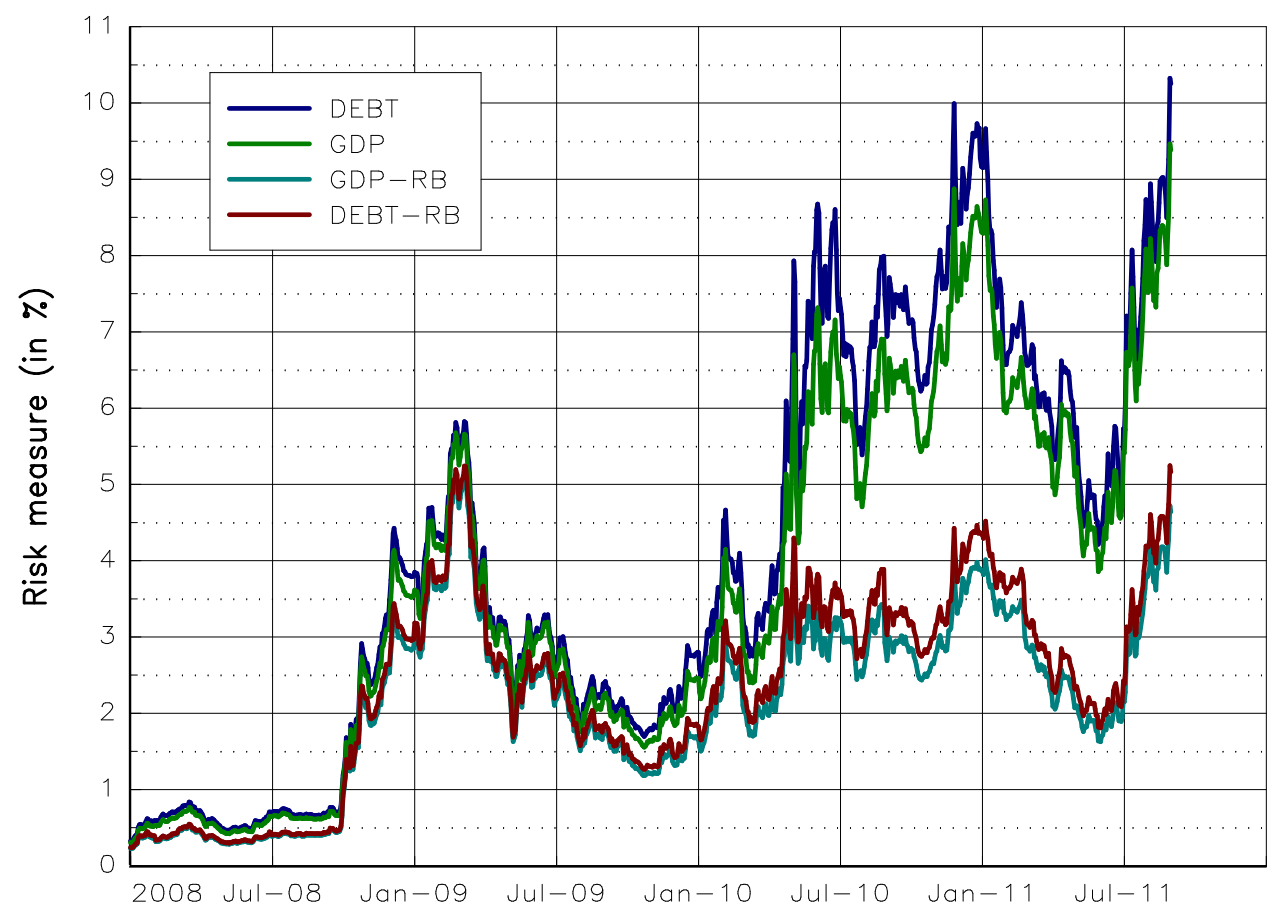

Figure 9: Evolution of the GIIPS risk contribution

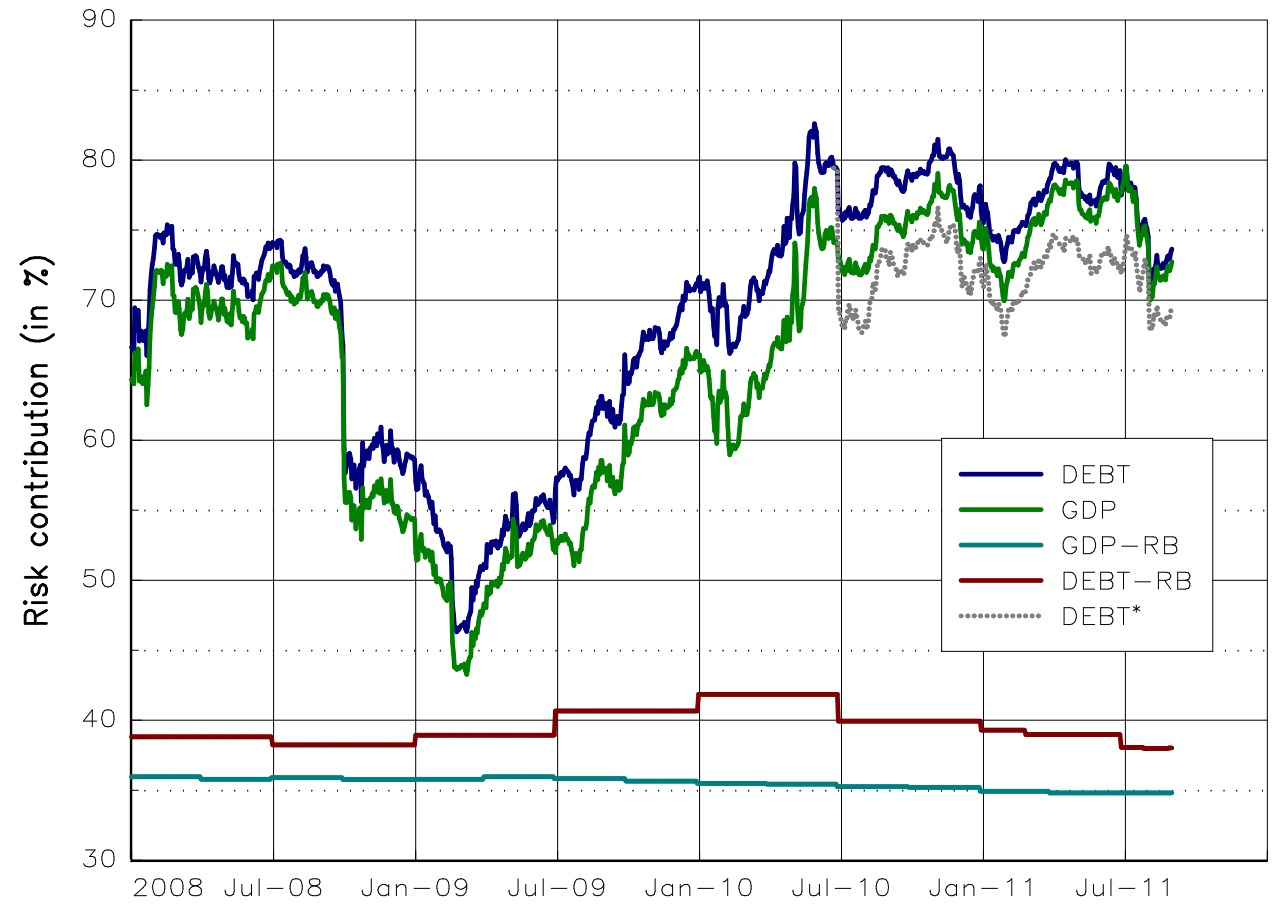


portfolio corresponds to a portfolio invested in only one country's debt. We observe in Table 11 that risk-based index approaches may lead to more concentrated portfolios in terms of weights. However the concentration in terms of risk is decreased when compared to debtbased (capitalisation) weighting. One of the main advantages of the risk budgeting approach comes from its dynamic allocation process, one which adapts to prevailing sovereign risk. By integrating the sovereign risk dimension in the investment process, indices based on risk budgeting also fit the definition of risk-based portfolios (Demey et al., 2010).

\subsection{With respect to active management}

In Figure 10, we report the NAV of the 218 funds available in the Morningstar database under the "Bond Euro Government" category. We also report the different performance quantiles $(10 \%, 25 \%, 50 \%, 75 \%$ and $90 \%)$ of these funds. We observe a high dispersion of performance between the top $10 \%$ and the bottom $10 \%$.

Many studies agree that on average mutual funds underperform passive benchmarks by a statistically and economically significant margin ${ }^{18}$. It is particularly true for the equity asset class, but it is less verified for the bond asset class. In our example, if we accept the academic rule that the average performance of active management (represented by the quantile 50\%)) is equal to the performance of the benchmark (represented by the DEBT indexation) minus the fees, we obtain an implied fees ratio equal to 36 bps per year. This academic rule seems to be verified. It is interesting to notice that risk-based indexations favorably compare with the top $10 \%$ best funds of active management.

Figure 10: Comparison of bond indexes with active management

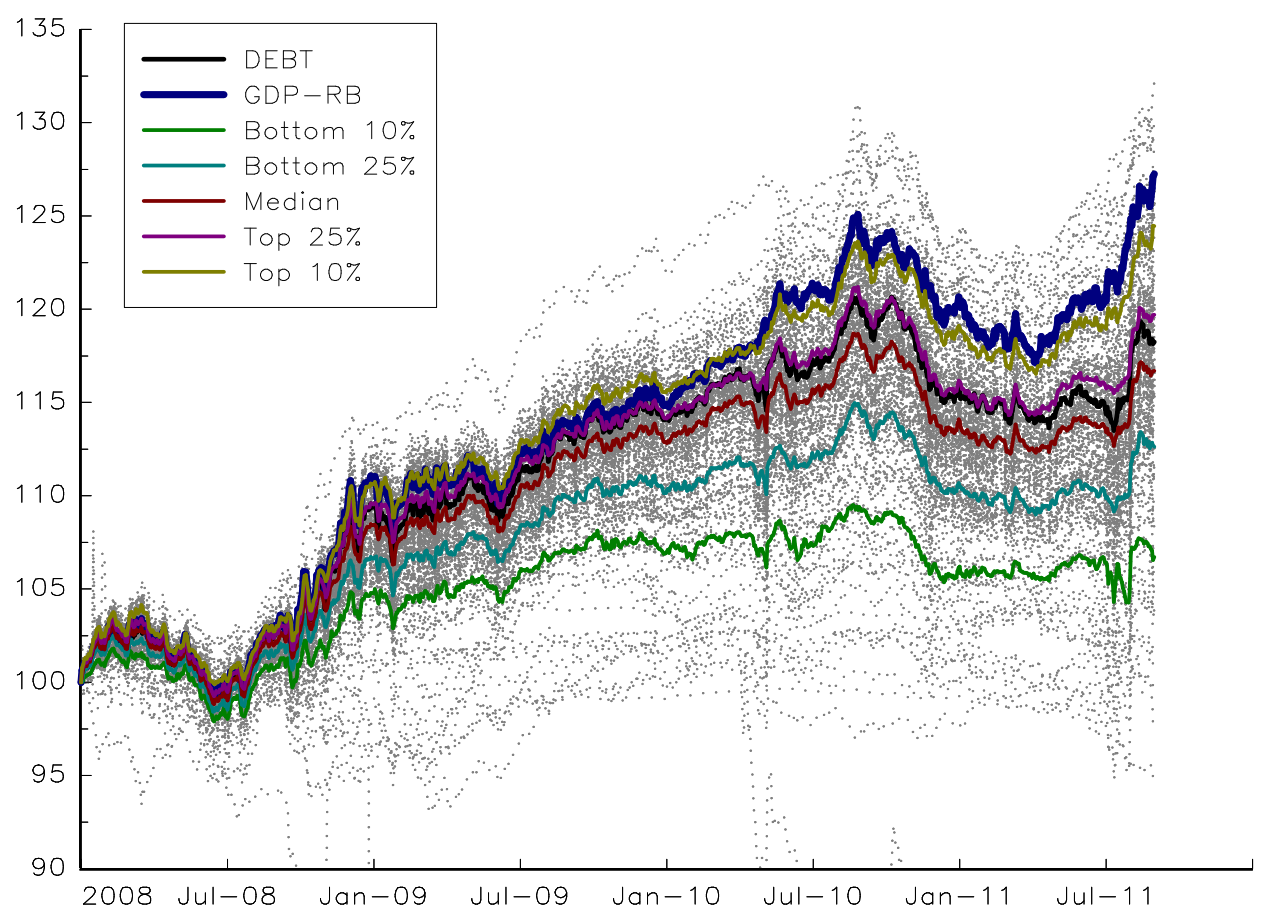

\footnotetext{
${ }^{18}$ See Hereil et al. (2010) for a survey.
} 


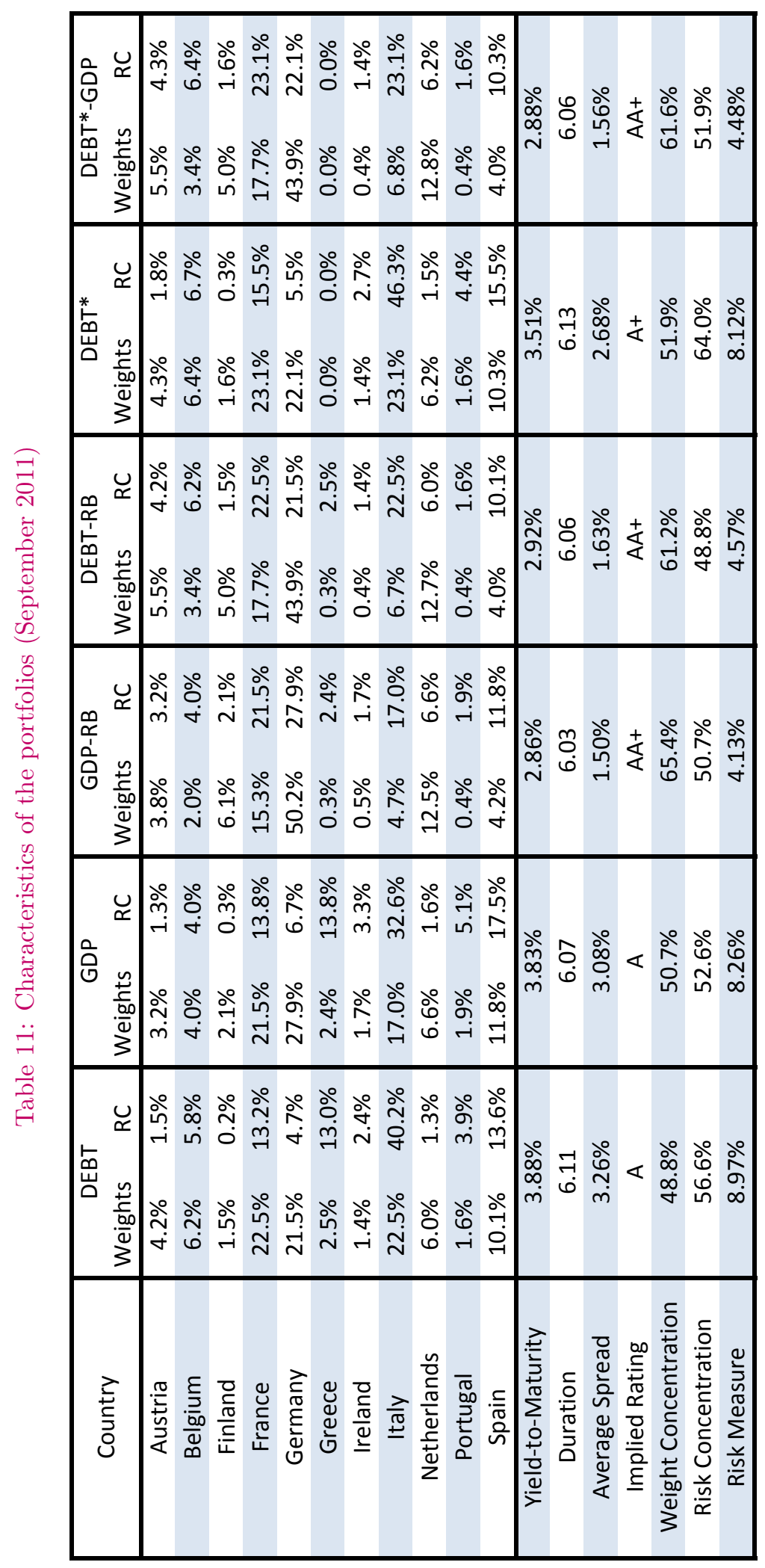




\section{Conclusion}

In this article, we present a useful framework to analyze the sovereign risk of a bond portfolio. By defining the credit risk of a bond portfolio as the volatility of the CDS basket which would perfectly hedge the sovereign risk of the portfolio, we can compute the sovereign risk contribution of each country and monitor it across time. Using this decomposition, we show that indexation based on risk budgeting techniques may be an efficient alternative to the traditional capitalisation-based approach to indexation. We also show that fundamental indexation is not enough and must be supplemented by risk-based methods.

We focus here on portfolios of sovereign bonds and on credit risk. However, this approach may be easily extended to take into account other risks (e.g. interest rates or foreign exchange) or to be applied to other asset classes (e.g. corporate or high yield bonds). In this last case, bond indexes based on risk budgeting techniques present an interesting feature

from a Solvency II point of view because they will need less capital requirements compared to traditional bond indexes. 


\section{References}

[1] ARnott R.D. (2009), Bonds: Why Bother?, Journal of Indexes, 12(3), pp. 10-17.

[2] Arnott R.D. (2010), Debt Be Not Proud, Journal of Indexes, 13(6), pp. 10-17.

[3] Arnott R.D., Hsu J.C., Li F. and Shepherd S.D. (2010), Valuation-Indifferent Weighting for Bonds, Journal of Portfolio Management, 36(3), pp. 117-130.

[4] Arnott R.D., Hsu J.C. and Moore P. (2005), Fundamental Indexation, Financial Analysts Journal, 61(2), pp. 83-99.

[5] Artzner A., Delbaen F., Eber J.-M. and Heath D. (1999), Coherent Measures of Risk, Mathematical Finance, 9(3), pp. 203-228.

[6] Blake C.R., Elton E.J. and Gruber M.J. (1993), The Performance of Bond Mutual Funds, Journal of Business, 66(3), pp. 371-403.

[7] Brodsky B., Flannery G. and Mesrour S. (2011), Introducing the BlackRock Sovereign Risk Index: A More Comprehensive View of Credit Quality, BlackRock Investment Institute, White Paper.

[8] Bruder B., Hereil P. and Roncalli T. (2011), Mesurer et gérer le risque de crédit souverain de la zone euro, Revue Banque, 740, pp. 48-50.

[9] Bruder B., Hereil P. and Roncalli T. (2011), Managing Sovereign Credit Risk, Journal of Indexes Europe, 1(4), pp. 20-27.

[10] Cantor R. and Packer F. (1996), Determinants and Impact of Sovereign Credit Rating, Federal Reserve Bank of New York Economic Policy Review, 2(2), pp. 1-15.

[11] Choueifaty Y. and Coignard Y. (2008), Towards Maximum Diversification, Journal of Portfolio Management, 35(1), pp. 40-51.

[12] Clarke R., De Silva H. and Thorley S. (2006), Minimum-variance Portfolios in the U.S. Equity Market, Journal of Portfolio Management, 33(1), pp. 10-24.

[13] Crocketr A. (1997), Why Is Financial Stability a Goal of Public Policy?, Federal Reserve Bank of Kansas City Economic Review, Q IV, pp. 5-22.

[14] Demey P., Maillard S. and Roncalli T. (2010), Risk-Based Indexation, Lyxor White Paper Series, 1, www. Iyxor.com.

[15] DeMiguel V., Garlappi L. and Uppal R. (2009), Optimal Versus Naive Diversification: How Inefficient is the 1/N Portfolio Strategy?, Review of Financial Studies, 22, pp. 1915-1953.

[16] Di Cesare A. (2006), Do Market-based Indicators Anticipate Rating Agencies? Evidence for International Banks, Economic Notes, 35(1), pp. 121-150.

[17] Ejsing J. and Lemke W. (2011), The Janus-Headed Salvation: Sovereign and Bank Credit Risk Premia during 2008-2009, Economics Letters, 110(1), pp. 28-31.

[18] Eychenne K., Martinetti S. and Roncalli T. (2011), Strategic Asset Allocation, Lyxor White Paper Series, 6, www.Iyxor.com. 
[19] Eychenne K., Martinetti S. and Roncalli T. (2011), Strategic Asset Allocation: An Update following the Sovereign Debt Crisis, www.Iyxor.com.

[20] Gilles C. and LeRoy S.F. (1997), Bubbles as Payoffs at Infinity, Economic Theory, 9(2), pp. 261-281.

[21] Goltz F. and Campani C.H. (2011), A Review of Corporate Bond Indices: Construction Principles, Return Heterogeneity, and Fluctuations in Risk Exposures, EDHEC Risk Institute.

[22] Gray D.F., Bodie Z. and Merton R.C. (2007), Contingent Claims Approach to Measuring and Managing Sovereign Risk, Journal of Investment Management, 5(4), pp. $5-28$.

[23] Hagan P.S., Kumar D., Lesniewski A.S. and Woodward D.E. (2002), Managing Smile Risk, Wilmott Magazine, July, pp. 84-108.

[24] Hilscher J. and Nosbusch Y. (2010), Determinants of Sovereign Risk: Macroeconomic Fundamentals and the Pricing of Sovereign Debt, Review of Finance, 14, pp. $235-262$.

[25] Hereil P., Moussavi N., Mitaine P. and Roncalli T. (2010), Mutual Fund Ratings and Performance Persistence, Lyxor White Paper Series, 3, www.Iyxor.com.

[26] Kindleberger C.P. (1939), Speculation and Forward Exchange, Journal of Political Economy, 47(2), pp. 163-181.

[27] Kindleberger C.P. (2005), Manias, Panics, and Crashes: A History of Financial Crises, John Wiley \& Sons, fifth edition (first edition in 1978).

[28] Krugman P. (2009), The Return of Depression Economics and the Crisis of 2008, W.W. Norton \& Company, (first edition in 1999).

[29] Longstaff F.A., Pan J., Pedersen L.H. and Singleton K.J. (2007), How Sovereign is Sovereign Credit Risk?, NBER Working Paper, No. 13658.

[30] Maillard S., Roncalli T. and Teiletche J. (2010), The Properties of Equally Weighted Risk Contributions Portfolios, Journal of Portfolio Management, 36(4), pp. 60-70.

[31] Martellini L. (2008), Toward the Design of Better Equity Benchmarks, Journal of Portfolio Management, 34(4), pp. 1-8.

[32] Merton R.C. (1974), On the Pricing of Corporate Debt: The Risk Structure of Interest Rates, Journal of Finance, 29(2), pp. 449-470.

[33] Meucci A. (2005), Risk and Asset Allocation, Springer.

[34] Mundell R.A. (1961), A Theory of Optimum Currency Areas, American Economic Review, 51(4), pp. 657-665.

[35] Reinhart C.M. and Rogoff K.S. (2009), This Time Is Different: Eight Centuries of Financial Folly, Princeton University Press.

[36] Reilly F.K., Kao G.W. and Wright D.J. (1992), Alternative Bond Market Indexes, Financial Analysts Journal, 48(3), pp. 44-58. 
[37] Roncalli T. (2011), Understanding the Impact of Weights Constraints in Portfolio Theory, Working Paper, ssrn.com/abstract $=1761625$.

[38] Scheren B. (2007), Portfolio Construction \& Risk Budgeting, third edition, Risk Books, 2007.

[39] Spaventa L. (1987), The Growth of Public Debt: Sustainability, Fiscal Rules, and Monetary Rules, Staff Papers - International Monetary Fund, 34(2), pp. 374-399.

[40] Toloui R. (2010), Time To Rethink Bond Indexes?, Journal of Indexes, 13(5), pp. 26-29.

[41] Wyplosz C. (1999), International Financial Instability, in Kaul I., Stern M. and Grunberg I. (eds), International Development Cooperation and Global Public Goods: Toward Sustainable Development in the 21st Century, Oxford University Press, pp. 152-189. 


\section{A Appendix}

\section{A.1 Maximum likelihood of the diffusion process for modeling spreads}

We assume that we observe spreads at some known dates $t_{0}, \ldots, t_{m}$. Let $S_{i, j}$ be the observed spread for the $i^{\text {th }}$ country at date $t_{j}$. The log-likelihood function for the $i^{\text {th }}$ country is given by the following formula:

$$
\begin{gathered}
\ell=-\frac{m}{2} \ln 2 \pi-m \ln \sigma_{i}^{S}-\frac{1}{2} \sum_{j=1}^{m} \ln \left(t_{j}-t_{j-1}\right)- \\
\beta_{i} \sum_{j=1}^{m} \ln S_{i, j-1}-\frac{1}{2} \sum_{j=1}^{m} \frac{\left(S_{i, j}-S_{i, j-1}\right)^{2}}{\left(\sigma_{i}^{S} S_{i, j-1}^{\beta_{i}}\right)^{2}}
\end{gathered}
$$

We estimate the coefficient $\beta_{i}$ by maximizing the concentrated log-likelihood function. Figure 10 shows the maximum likelihood estimation of $\beta_{i}$ for the period January 2008-August 2011.

Table 12: Results for the period January 2008 - August 2011

\begin{tabular}{|c|ccccccccccc|c|}
\hline Country & AT & BE & Fl & FR & DE & GR & IE & IT & NL & PT & ES & Average \\
\hline estimate & 0.996 & 1.017 & 0.816 & 0.786 & 0.899 & 1.070 & 0.836 & 1.157 & 0.793 & 1.013 & 1.148 & 0.957 \\
std-dev. & $1.10 \%$ & $2.00 \%$ & $1.60 \%$ & $1.60 \%$ & $2.00 \%$ & $1.10 \%$ & $0.70 \%$ & $1.70 \%$ & $0.90 \%$ & $1.10 \%$ & $2.10 \%$ & $1.45 \%$ \\
\hline
\end{tabular}

\section{A.2 Risk decomposition of the volatility risk measure}

We consider a portfolio $x=\left(x_{1}, \ldots, x_{n}\right)$ of $n$ assets. Let $\Sigma$ be the covariance matrix of assets. The volatility of the portfolio is then equal to:

$$
\sigma(x)=\sqrt{x^{\top} \Sigma x}
$$

We deduce that the marginal volatility is:

$$
\frac{\partial \sigma(x)}{\partial x}=\frac{\Sigma x}{\sqrt{x^{\top} \Sigma x}}
$$

We define the risk contribution as the product of the weight times the marginal volatility:

$$
\begin{aligned}
\mathrm{RC}_{i} & =x_{i} \cdot \frac{\partial \sigma(x)}{\partial x_{i}} \\
& =x_{i} \cdot \frac{(\Sigma x)_{i}}{\sqrt{x^{\top} \Sigma x}}
\end{aligned}
$$

We verify that the sum of risk contributions is exactly equal to the volatility risk measure:

$$
\begin{aligned}
\sum_{i=1}^{m} \mathrm{RC}_{i} & =\sum_{i=1}^{m} x_{i} \cdot \frac{(\Sigma x)_{i}}{\sqrt{x^{\top} \Sigma x}} \\
& =x^{\top} \frac{\Sigma x}{\sqrt{x^{\top} \Sigma x}} \\
& =\sqrt{x^{\top} \Sigma x} \\
& =\sigma(x)
\end{aligned}
$$

